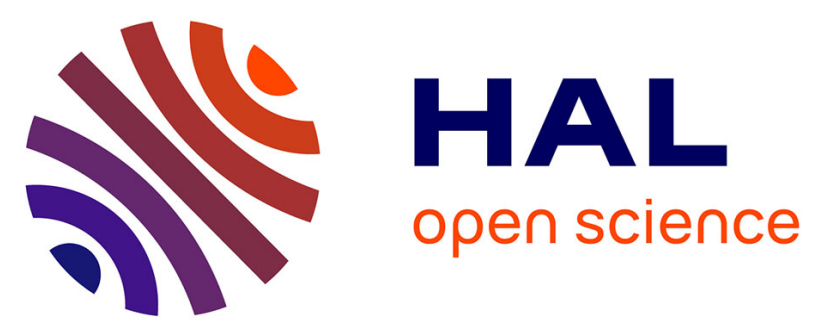

\title{
Baicalein-modified hydroxyapatite nanoparticles and coatings with antibacterial and antioxidant properties
}

Estelle Palierse, Christophe Hélary, Jean-Marc Krafft, Isabelle Génois, Sylvie

Masse, Guillaume Laurent, Maria I Alvarez Echazu, Mohamed Selmane, Sandra Casale, Laetitia Valentin, et al.

\section{To cite this version:}

Estelle Palierse, Christophe Hélary, Jean-Marc Krafft, Isabelle Génois, Sylvie Masse, et al.. Baicaleinmodified hydroxyapatite nanoparticles and coatings with antibacterial and antioxidant properties. Materials Science and Engineering: C, 2021, 118, pp.111537, 1-13. 10.1016/j.msec.2020.111537. hal-02946075

\section{HAL Id: hal-02946075 \\ https://hal.sorbonne-universite.fr/hal-02946075}

Submitted on 22 Sep 2020

HAL is a multi-disciplinary open access archive for the deposit and dissemination of scientific research documents, whether they are published or not. The documents may come from teaching and research institutions in France or abroad, or from public or private research centers.
L'archive ouverte pluridisciplinaire HAL, est destinée au dépôt et à la diffusion de documents scientifiques de niveau recherche, publiés ou non, émanant des établissements d'enseignement et de recherche français ou étrangers, des laboratoires publics ou privés. 


\section{Baicalein-modified hydroxyapatite nanoparticles and coatings with antibacterial and antioxidant properties}

Estelle Palierse, ${ }^{\mathrm{a}, \mathrm{b}}$ Christophe Hélary, ${ }^{\mathrm{a}}$ Jean-Marc Krafft, ${ }^{\mathrm{b}}$ Isabelle Génois, ${ }^{\mathrm{a}}$ Sylvie Masse, ${ }^{\mathrm{a}}$ Guillaume Laurent, ${ }^{\mathrm{a}}$ Maria I. Alvarez Echazu, ${ }^{\mathrm{c}}$ Mohamed Selmane, ${ }^{\mathrm{d}}$ Sandra Casale, ${ }^{\mathrm{b}}$ Laetitia Valentin, ${ }^{\mathrm{b}}$ Antoine Miche, ${ }^{\mathrm{b}}$ Ben C.L. Chan, ${ }^{\mathrm{e}}$ Clara B.S. Lau, ${ }^{\mathrm{e}}$ Margaret $\mathrm{Ip},{ }^{\mathrm{f}}$ Martin F. Desimone, ${ }^{\mathrm{c}}$ Thibaud Coradin, ${ }^{\mathrm{a}, *}$ Claude Jolivalt ${ }^{\mathrm{b}, *}$

a Sorbonne Université, CNRS, Laboratoire de Chimie de la Matière Condensée de Paris (LCMCP), 4 place Jussieu, 75005 Paris, France

${ }^{\mathrm{b}}$ Sorbonne Université, CNRS, Laboratoire de Réactivité de Surface (LRS), 4 place Jussieu, 75005 Paris, France

c Universidad de Buenos Aires, Consejo Nacional de Investigaciones Científicas y Técnicas (CONICET), Instituto de la Química y Metabolismo del Fármaco (IQUIMEFA), Facultad de Farmacia y Bioquímica, Buenos Aires, Argentina

${ }^{d}$ Sorbonne Université, Institut des Matériaux de Paris Centre (IMPC), 4 place Jussieu, 75005 Paris, France

${ }^{e}$ Institute of Chinese Medicine and State Key Laboratory of Research on Bioactivities and Clinical Applications of Medicinal Plants, The Chinese University of Hong Kong, Shatin, New Territories, Hong Kong.

${ }^{f}$ Department of Microbiology, Faculty of Medicine, The Chinese University of Hong Kong, Shatin, New Territories, Hong Kong

Corresponding authors: Claude Jolivalt and Thibaud Coradin

claude.jolivalt@sorbonne-universite.fr

thibaud.coradin@ sorbonne-universite.fr 


\begin{abstract}
Aseptic loosening and bacterial infections are the two main causes of failure for metallic implants used for joint replacement. A coating that is both bioactive and possesses antimicrobial properties may address such shortcomings and improve the performance of the implant. We have sought to study the properties of combining hydroxyapatite-based nanoparticles or coatings with baicalein, a plant-extracted molecule with both antibacterial and antioxidant properties. (B-type) carbonated hydroxyapatite nanoparticles prepared by a chemical wet method could subsequently adsorbed by soaking in a baicalein solution. The amount of adsorbed baicalein was determined to be $63 \mathrm{mg} \cdot \mathrm{g}^{-1}$ by thermogravimetric measurements. In a second approach, baicalein was adsorbed on a biomimetic calciumdeficient hydroxyapatite planar coating (12 $\mu \mathrm{m}$ thick) deposited on Ti6Al4V alloy from an aqueous solution of calcium, phosphate, sodium and magnesium salts. Soaking of the hydroxyapatite coated on titanium alloy in a baicalein solution induced partial dissolution/remodeling of the upper surface of the coating. However, the observed remodeling of the surface was much more pronounced in the presence of a baicalein solution, compared to pure water. The presence of adsorbed baicalein on the HAp layer, although it could not be precisely quantified, was assessed by XPS and fluorescence analysis. Planar coatings exhibited significant antibacterial properties against Staphylococcus epidermidis. Baicaleinmodified nanoparticles exhibited significant antioxidant properties. These results illustrate the potential of hydroxyapatite used as a carrier for natural biologically-active molecules and also discuss the challenges associated with their applications as antibacterial agents.
\end{abstract}

Keywords: Titanium alloy; Hydroxyapatite; baicalein; Antibacterial activity; Antioxidant properties 


\section{Introduction}

With ageing of population and recrudescence of arthrosic pathologies at early ages, the demand for biomaterials is constantly increasing, especially in the field of joint replacements (hip, knee). The requirements for physical properties do not leave many options in the choice of the material, only metals having acceptable stress and fatigue resistance. Due to the necessity of biocompatibility, titanium (Ti) and its alloys are widely used. However, several studies underline the increasing rate of revisions of arthroplasties over these last 20 years from implant failure [1], primarily caused by aseptic loosening and development of infections [2]. Aseptic loosening can occur on an implant with or without cement. The cement is used to fix the prosthesis in the implantation site, but the repetition of mechanical stress during locomotion degrades the bone-cement and cement-implant interfaces, leading to the disintegration of the cement and the production of loose pieces which can trigger an inflammatory response. In cementless arthroplasty, the loosening is related to the ability of osseointegration of the implant material into the bone.

Ti-based materials are currently the most commonly used to design the sections of implants that are in direct contact within bone [3]. However, they are not bioactive (i.e. do not favour bone growth) as such. Modifications of their surface by physical or chemical methods are possible to improve the osseointegration. Polishing techniques [4,5], or laser treatments [6] may be used to enhance the roughness and the hydrophilicity of the metallic substrate, that are known to induce better cell adhesion. Anodization of the surface to form titanium oxide nanotubes is also developed [7-9], as $\mathrm{TiO}_{2}$ nanotubes enhance cell growth. Another approach is to coat the metallic surface with calcium phosphate material, due to its similarity with bone. In particular, the use of hydroxyapatite-based coatings is widespread [10,11], as they are close 
in composition to the bone mineral phase and show high bioactivity [12]. Such coatings are now clinically used for cementless arthroplasty, with partially or fully coated femoral stem $[13,14]$. Furthermore, the possibility to incorporate active molecules or biological agents on or within hydroxyapatite coatings may provide antimicrobial activity to the surfaces of the implant [15-17]. This strategy enables higher concentrations to be achieved on the surfaces for antimicrobial activity. One possible strategy is to substitute $\mathrm{Ca}^{2+}$ with antibacterial metallic ions like $\mathrm{Ag}^{+}[18]$ or $\mathrm{Cu}^{2+}$ [19-21], but with the drawbacks of possible cytotoxicity associated with these metals. A recent approach is to synthesize $\mathrm{TiO}_{2}$ nanotubes at the surface of the titanium substrate, followed by the loading of the nanotubes by Ag-Si-Sr-substituted HAp nanoparticles, which enables an inhibition of bacterial activity while enhancing the biocompatibility [8]. Another possibility is to incorporate antibiotics directly in the hydroxyapatite coating, leading to significantly higher antibacterial effect of the material both in vivo and in vitro $[15,22-26]$.

However, with increasing antibacterial resistance, described by the World Health Organization as "one of the biggest threats to global health, food security, and development today", it is necessary either to find alternative antibacterial strategies or to identify drugs active against resistant strains [27,28]. In this context, natural antibiotics extracted from plants, in particular secondary metabolites such as flavonoids that are known to be involved in plant resistance mechanisms against microorganisms, appear as particularly promising [29,30]. For instance, baicalein (Fig.1), extracted from the root of the plant Scutellaria baicalensis, is known in the Chinese Pharmacopeia for centuries for its anti-inflammatory, antioxidant, antiviral, anticancer and antibacterial properties [31-34]. Its antibacterial activity was tested against sensitive Staphylococcus aureus and Methicillin-Resistant S. aureus (MRSA) [35,36]. Baicalein alone was able to eradicate a 7-days biofilm in a dose-dependent manner, for concentrations above its minimal inhibitory concentration (MIC) [35]. Used in 
combination with ciprofloxacin, baicalein at concentration below MIC was able to restore the antibacterial activity of ciprofloxacin against MRSA. Additionally, a synergistic effect was observed against ciprofloxacin-resistant strains [36].<smiles>O=c1cc(-c2ccccc2)oc2cc(O)c(O)c(O)c12</smiles>

Fig.1 Structure of baicalein (BE)

We present here the combination of baicalein and hydroxyapatite, with the goal of enhancing the osseointegration and the antibacterial properties of orthopaedic implants. The strategy was to adsorb baicalein to hydroxyapatite by soaking the material into a baicalein solution. Two hydroxyapatite shaping was used: nanoparticles that could be used to cover metallic substrates after dip or spin coating processes [37], and planar hydroxyapatite layer deposited on a titanium allow coupon using a biomimetic method previously described in the literature [38]. The antioxidant and antibacterial activities of both modified nanoparticles and coatings after adsorption were studied. This study discusses the potential and limitations of the use of such natural drugs to confer additional biological functionalities to hydroxyapatite materials designed as metallic implants coatings.

\section{Methods}

\subsection{Chemicals}

Baicalein (BE) was purchased from TCI Europe (Zwijndrecht, Belgium) and stock solution at $0.1 \mathrm{M}$ prepared in dimethylsulfoxide (DMSO) or methanol for ESI-MS analysis. 
Calcium chloride dihydrate was obtained from Jessen Chemica. Sodium chloride and potassium chloride were purchased from Carlo Erba. $\mathrm{NaHCO}_{3}$, TRIS and sodium hydroxide were obtained from Sigma. Potassium phosphate monobasic, magnesium chloride hexahydrate and sodium sulfate are obtained from Prolabo. $10 \mathrm{~mm} * 10 \mathrm{~mm}$ Ti6Al4V titanium alloy plates with $1 \mathrm{~mm}$ thickness were obtained from Goodfellow Cambridge Limited (Huntigdon, UK). Before use, they were polished by \#500, \#800 and \#1200 silicon carbide (SiC) disk, washed successively in acetone, ethanol and distilled water under ultrasound for 15 minutes, following by a hydroxylation in sodium hydroxide $5 \mathrm{M}$ at $60{ }^{\circ} \mathrm{C}$ for 24 hours.

\subsection{Synthesis of hydroxyapatite nanoparticles}

Hydroxyapatite was synthesized by co-precipitation following the chemical wet method previously reported [39]. Briefly, $0.1 \mathrm{~mol} \mathrm{of} \mathrm{Ca}(\mathrm{OH})_{2}(7.4 \mathrm{~g})$ was dissolved in 100 $\mathrm{mL}$ of distilled water for 1.30 hour, and $0.06 \mathrm{~mol}(6.9 \mathrm{~g})$ of $\mathrm{NH}_{4} \mathrm{H}_{2} \mathrm{PO}_{4}$ was dissolved in 50 $\mathrm{mL}$ of water. Ammonium dihydrogen phosphate solution was added to calcium solution, and the medium was left to react for $48 \mathrm{~h}$ at $25^{\circ} \mathrm{C}$ under stirring. Temperature was controlled by a thermostat bath. After reaction, white particles were recovered by centrifugation at $5000 \mathrm{rpm}$ for 5 minutes, followed by three washes with distilled water. The powder was dried at $100{ }^{\circ} \mathrm{C}$ for 24 hours. For sorption studies, $10 \mathrm{mg}$ of ground HAp particles were re-suspended in a 200 $\mathrm{mL}$ solution of $\mathrm{BE}$ in distilled water $(\mathrm{pH} \approx 5)$. The $\mathrm{BE}$ concentration was set to $0.05 \mathrm{mM}$ as it is near to the limit of solubility of $\mathrm{BE}$ in water, corresponding to an initial molar ratio between $\mathrm{Ca}$ and $\mathrm{BE}$ of 1 . After 24 hours of contact under stirring at room temperature, particles were recovered by filtration, and dried at $100{ }^{\circ} \mathrm{C}$ for 24 hours (Fig.2a)

\subsection{Characterization of hydroxyapatite nanoparticles}

X-ray diffractograms (XRD) were recorded on a D8 Advance powder diffractometer (Bruker AXS, GmbH, Karlsruhe, Germany), equipped with a $\mathrm{Cu}$ source $\left(\mathrm{CuK}_{\alpha}\right.$ radiation at $1.54 \AA$ ) and one-dimensional detector LynxEye in a Bragg-Brentano $2 \Theta-2 \Theta$ geometry, 
between $7^{\circ}$ and $80^{\circ}$ with a variable slit V12. For powder analysis, step was $0.03^{\circ} . \mathrm{s}^{-1}$ and scan speed 1 s.point ${ }^{-1}$. Scherrer equation [40] was employed to calculate the crystallite size of products (i.e. nano-HA) for each experiment: $D=—$, where $\lambda$ represents the wavelength of $\mathrm{Cu} \mathrm{K \alpha}$ i.e. $0.154 \mathrm{~nm}, \mathrm{~B}$ is the peak width at half-maximum intensity of (211) plane of HA in radians and $\theta$ is the angle of the latter peak in degrees.

Thermogravimetric analysis (TGA) was performed with a SDT Q600 apparatus from TA Instruments, between $25{ }^{\circ} \mathrm{C}$ and $600{ }^{\circ} \mathrm{C}$, with a ramp of $10{ }^{\circ} \mathrm{C} / \mathrm{min}$, under air. Sample weights were typically comprised between 10 and $20 \mathrm{mg}$. Surface specific area was measured with a physisorption apparatus (Belsorpmax), by measuring the adsorbed quantity of $\mathrm{N}_{2}$ in function of pressure, at $\mathrm{T}=77 \mathrm{~K}$. Before measurement, vacuum degree was $3.202 \times 10^{-6} \mathrm{~Pa}$. Sample weight was $0.9340 \mathrm{~g}$. Transmission electron microscopy (TEM) images of samples were obtained with Tecnaï spirit G2 microscope with a Gatan Orius camera

Solid state NMR studies were performed on an Avance III Bruker spectrometer operating at $7.0 \mathrm{~T}$ (corresponding to $300.3,121.6,75.5 \mathrm{MHz}$ for ${ }^{1} \mathrm{H},{ }^{31} \mathrm{P}$ and ${ }^{13} \mathrm{C}$ nuclei, respectively) equipped with a $4 \mathrm{~mm}$ Magic Angle Spinning (MAS) broadband dual probehead. Samples were inserted into zirconia rotors and spun at MAS $=12 \mathrm{kHz} .{ }^{1} \mathrm{H}$ experiments were acquired either with probe signal suppression (DEPTH pulse sequence)[41], or with rotor synchronised Hahn echoes [42] at 2x1 to 2x10 turns. 16 scans were recorded with a relaxation delay $\mathrm{RD}=1 \mathrm{~s}$, a $90^{\circ}$ pulse and a Line Broadening $\mathrm{LB}=10 \mathrm{~Hz}$. For $\left\{{ }^{1} \mathrm{H}\right\}-{ }^{13} \mathrm{C}$ experiments, Cross Polarization $(\mathrm{CP})$ was used with a contact time $\mathrm{t}_{\mathrm{cp}}=2 \mathrm{~ms}, 47752$ scans and $\mathrm{LB}=50 \mathrm{~Hz}$. Before acquisition, the probe was cleaned with nitric acid at $\mathrm{pH}=4.5$ to avoid any residual ${ }^{13} \mathrm{C}$ pollution. Two-Dimensional (2D) $\left\{{ }^{1} \mathrm{H}\right\}-{ }^{31} \mathrm{P}$ HETeronuclear CORrelation (HETCOR) maps [43] were obtained with a Hahn echo at 2x3 turns to allow $T_{2}$ transversal relaxation before $C P$ with a contact time $t_{\mathrm{cp}}=1$ or $10 \mathrm{~ms}, 256$ 
scans, 180 slices, STATES-TPPI quadrature mode [44] and LB $=50 \mathrm{~Hz}$ in both dimensions. For both ${ }^{13} \mathrm{C}$ and ${ }^{31} \mathrm{P} \mathrm{CP}$ experiments, a 95-105\% ramp was used during $\mathrm{CP}$ step and SPINAL64 decoupling [45] was applied during acquisition. ${ }^{1} \mathrm{H}$ radio frequency was set at $v_{1 \mathrm{H}}=70 \mathrm{kHz}$ for ${ }^{1} \mathrm{H}$ and $v_{\mathrm{X}}=82 \mathrm{kHz}$ for the other nucleus. ${ }^{1} \mathrm{H}$ and ${ }^{13} \mathrm{C}$ chemical shift where referenced to tetramethylsilane, whereas ${ }^{31} \mathrm{P}$ was referenced to $85 \%$ phosphoric acid.

Baicalein release from HAp particles in PBS was studied by HPLC. $10 \mathrm{mg}$ of particles

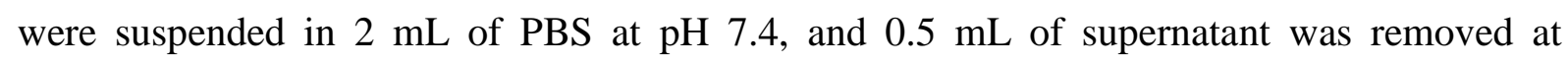
different times for HPLC analysis, and replaced by fresh PBS. Baicalein release was studied over 6 days. HPLC analysis was performed with reverse phase on a C18 column.

\subsection{Synthesis of hydroxyapatite coatings on titanium alloys}

Hydroxyapatite was synthesized on titanium alloy substrates in Simulated Body Fluid (SBF) concentrated 1.5-fold (1.5-SBF) (Supplementary Material, S1 for precise composition of 1.5-SBF). Samples were vertically immersed in the 1.5-SBF solution, with volume/surface ratio V/S $=25 \mathrm{~mL} \cdot \mathrm{cm}^{-2}$. Deposition was performed in high density polyethylene bottles (Thermo Scientific ${ }^{\mathrm{TM}}$ Nalgene ${ }^{\mathrm{TM}}$ Wide-Mouth HDPE Packaging Bottles). The solution was renewed every $48 \mathrm{~h}$ by freshly-prepared $1.5-\mathrm{SBF}$. Plates were withdrawn from the medium after 14 days, rinsed three times in distilled water and dried at room temperature for 24 hours. For baicalein adsorption, Ti alloy substrates coated with hydroxyapatite were then soaked in an aqueous solution of $\mathrm{BE}(0.1 \mathrm{mM})$ for 24 hours, with a volume $\mathrm{V}=2 \mathrm{~mL}$ for each sample (Fig.2b).

\subsection{Characterization of hydroxyapatite coatings}

XRD analysis of coatings was performed as previously described for nanoparticles except that the step was $0.05^{\circ} . \mathrm{s}^{-1}$ and scan speed was 0.1 s.point ${ }^{-1}$. The record was repeated 5 times to increase the signal to noise ratio. Raman spectra were collected with a Kaiser Optical 
system, Raman Analyzer RXN1 microprobe equipped with a laser diode at $785 \mathrm{~nm}(\mathrm{P}=10$ $\mathrm{mW}$, accumulation time: $10 \mathrm{~s}, 30$ scans per spectrum), and a Leica microscope with $\mathrm{x} 50$ objective. Fluorescence spectra of coatings were obtained with a Fluorolog 3 apparatus from HORIBA Jobin Yvon. Excitation was set at $\lambda_{\text {exc }}=300 \mathrm{~nm}$ with $5 \mathrm{~nm}$ of bandpass and emission spectrum was recorded between 320 and $650 \mathrm{~nm}$ with $1 \mathrm{~nm}$ of bandpass. Increment was set at $1.0 \mathrm{~nm}$ and integration time at $0.5 \mathrm{~s}$. The surface was tilted from the incident beam (source Xenon, $450 \mathrm{~W}$ ), and spectra were collected with an angle of $22^{\circ}$.

Morphology of coatings was observed by scanning electron microscopy on a Hitachi S-3400N microscope (acceleration voltage $10 \mathrm{kV}$, probe current 70). Samples were covered with carbon before imaging. Energy dispersive X-ray (EDX) spectroscopy was performed thanks to an Oxford instrument $-\mathrm{X}$ max (AZTEC software) and spectra were recorded at 4 different locations of the sample to check for homogeneity. Images of HAp coatings tilted with an angle of $45^{\circ}$ were recorded on a SEM-FEG Hitachi SU-70 with an acceleration voltage at $1 \mathrm{kV}$. TEM experiments were performed with a Jeol JEM 1011 instrument (tungsten filament and $100 \mathrm{kV}$ )

XPS spectra were collected on an Omicron Argus X-ray photoelectron spectrometer, using a monochromated $\mathrm{Al} \mathrm{K}_{\alpha}(\mathrm{h} v=1486.6 \mathrm{eV})$ radiation source having a $280 \mathrm{~W}$ electron beam power. The emission of photoelectrons from the sample was analyzed at a take-off angle of $45^{\circ}$ under ultra-high vacuum conditions $\left(1.10^{-7} \mathrm{~Pa}\right)$. XP spectra were collected at pass energy of $20 \mathrm{eV}$ for $\mathrm{C}_{1 \mathrm{~s}}, \mathrm{O}_{1 \mathrm{~s}}, \mathrm{Ti}_{2 \mathrm{p}}, \mathrm{Ca}_{2 \mathrm{p}}, \mathrm{P}_{2 \mathrm{p}}$, and $\mathrm{Mg}_{2 \mathrm{~s}}$ core XPS levels. After data collection, the binding energies were calibrated with respect to the binding energy of the $C_{1 s}$ peak at $284.7 \mathrm{eV}$. The peak areas were determined after subtraction of a Shirley background. The atomic ratio calculations were performed after normalization using Scofield factors. Spectrum processing was carried out using the Casa XPS software package. 
(a)

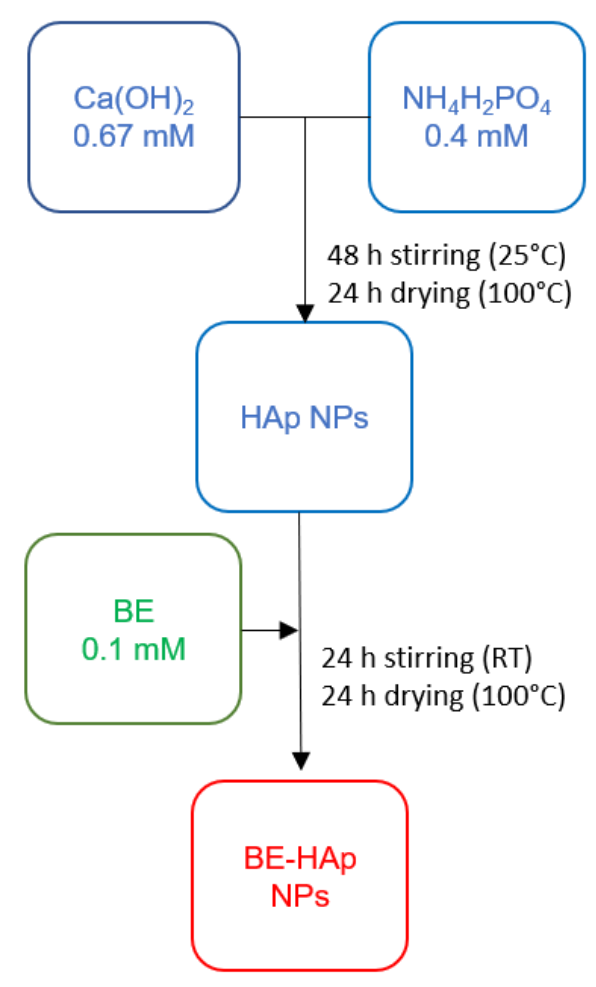

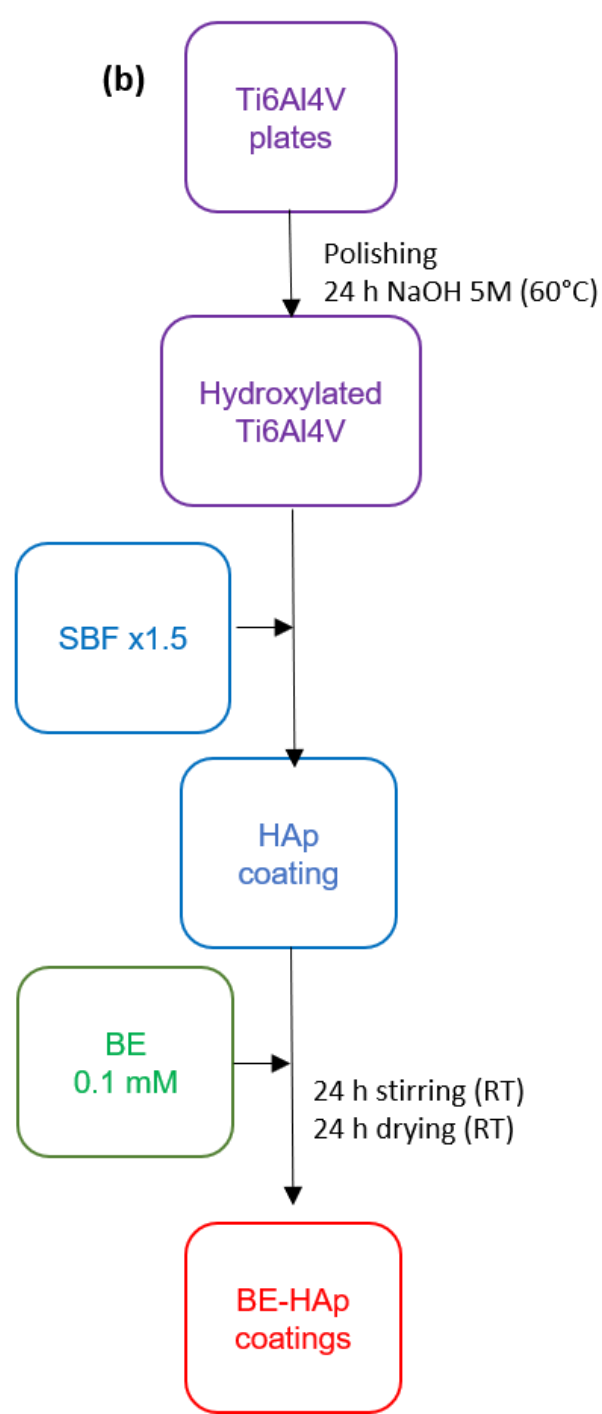

Fig.2 Experimental flow chart for the preparation of baicalein (BE)-hydroxyapatite (HAp) (a) nanoparticles (NPs) and (b) coatings.

\subsection{Antibacterial activity}

The minimum inhibitory concentration (MIC) of BE against Staphylococcus epidermidis CIP 105.777 was determined using a two-fold serial dilution method in 96-wells plates. $100 \mu \mathrm{L}$ of a bacterial inoculum of $1 \times 10^{6} \mathrm{CFU} \cdot \mathrm{mL}^{-1}$ was prepared from an overnight culture in sterile Mueller-Hilton broth $(\mathrm{MH})$ and dispensed in each of the wells of a given row 96-well microplate. $100 \mu \mathrm{L}$ of a BE solution $1.35 \mathrm{mg} / \mathrm{mL}$ (prepared from a $10 \mathrm{mg} \cdot \mathrm{mL}^{-1}$ stock solution in DMSO) was added in the first well of the row. After mixing, $100 \mu \mathrm{L}$ of the mixture was transferred in the second well. The series of two-fold dilutions was performed 
until the last well of the microwell plate. BE final concentrations in the wells ranged from 68 to $0.033 \mu \mathrm{g} \cdot \mathrm{mL}^{-1}$. The highest final DMSO concentration used $(5 \%)$ induced no significant bacterial growth inhibition. Growth of bacterial strains was visually assessed after 24 hours incubation at $37^{\circ} \mathrm{C}$. MIC was the minimal concentration of the tested compound that completely inhibited cell growth. MIC determination of ciprofloxacin $\left(0.0625 \mu \mathrm{g} \cdot \mathrm{mL}^{-1}\right.$ against S. epidermidis CIP 105.777) was performed as a control on each microplate. The accepted variance on MIC value can be estimated to a 2-fold difference due to the microdilution method used. Experiments were performed in duplicate.

Antibacterial properties of the nanoparticles were tested against S. epidermidis CIP 105.777. Two concentrations of (HAp + adsorbed BE) NPs were tested, $5 \mathrm{mg} \cdot \mathrm{mL}^{-1}$ and 25 mg.mL $L^{-1}$. NPs were incubated with bacterial suspension at $5 \times 10^{5} \mathrm{CFU}_{\mathrm{mL}} \mathrm{mL}^{-1}$ in $\mathrm{MH}$ culture broth for 16 hours at $37{ }^{\circ} \mathrm{C}$ on a rotative shaker (30 rpm). After 16 hours, suspensions were filtrated on a sterile filtration membrane (cellulose ester, $3 \mu \mathrm{m}$ porosity, Whatman Millipore). The membrane was then soaked in $2 \mathrm{~mL}$ of phosphate buffer saline (PBS) and sonicated during 5 minutes in order to resuspend bacteria. The obtained PBS solutions were then diluted to perform plate counting on solid $\mathrm{MH}$-agar medium and living bacteria were enumerated (in Colony Forming Unit) after 24 hours of incubation at $37^{\circ} \mathrm{C}$.

Antibacterial properties of the coatings were determined by dipping the BE-HAp covered Ti alloy substrates in $2 \mathrm{~mL}$ of S. epidermidis CIP 105.777 suspension $\left(5 \times 10^{4}\right.$ CFU.mL ${ }^{-1}$ ) in $\mathrm{MH}$ at $37^{\circ} \mathrm{C}$. After 16 hours, samples were rinsed carefully with PBS to remove bacteria that are weakly adsorbed to the surface. Plates were then soaked in $2 \mathrm{~mL}$ of PBS, and the surface was scratched before 5 min of sonication and again afterwards, in order to recover adhered bacteria. The obtained PBS solutions were then diluted to perform plate counting on solid MH-agar medium and living bacteria were enumerated (in Colony Forming Unit) after 24 hours of incubation at $37^{\circ} \mathrm{C}$. 


\subsection{Antioxidant activity}

Antioxidant potential of HAp NPs or coatings with adsorbed baicalein was tested using 2,2-diphenyl-1-picrylhydrazyle (DPPH) free radical scavenging method adapted from Blois [46,47]. For the NPs, the assay was performed as follows: $10 \mathrm{mg}$ of NPs were suspended in $1 \mathrm{~mL}$ of a 1:1 (v/v) mixture of TRIS buffer at pH 7.4 and DPPH $(100 \mu \mathrm{M}$ in ethanol). For coatings, each sample was immersed in $2 \mathrm{~mL}$ of the same mixture. Samples were incubated for 20 minutes in the dark and absorbance of the solution was recorded at 517 nm. DPPH absorbance reduction was calculated by the equation: \%reduction $=\left[1-\left(A_{\text {sample }} /\right.\right.$ $\left.\left.A_{\mathrm{DPPH}}\right)\right] \times 100$, with, $\mathrm{A}_{\text {sample }}$ the absorbance after $20 \mathrm{~min}$ in the dark and $\mathrm{A}_{\mathrm{DPPH}}$ the absorbance of DPPH solution before the addition of the solids. 


\section{Results}

\subsection{Hydroxyapatite nanoparticles}

Hydroxyapatite nanoparticles (HAp NP) were synthesized by a chemical wet method. The synthesis yield was $c a .60 \%$ assuming that only stoichiometric hydroxyapatite $\left(\mathrm{Ca}_{10}\left(\mathrm{PO}_{4}\right)_{6}(\mathrm{OH})_{2}\right)$ was formed. The X-ray diffractogram (Fig.3a) confirmed this hypothesis, by comparison to the PDF card 64-0738. TEM image as seen in Fig.3b showed plate-like nanoparticles $31 \pm 6 \mathrm{~nm}$ in length and $9 \pm 3 \mathrm{~nm}$ in width. Specific surface area calculated with the BET method was $160 \mathrm{~m}^{2} \cdot \mathrm{g}^{-1}$ and the average pore size, corresponding to inter-particle distance, was $15 \mathrm{~nm}$ (Supplementary Material, S2).

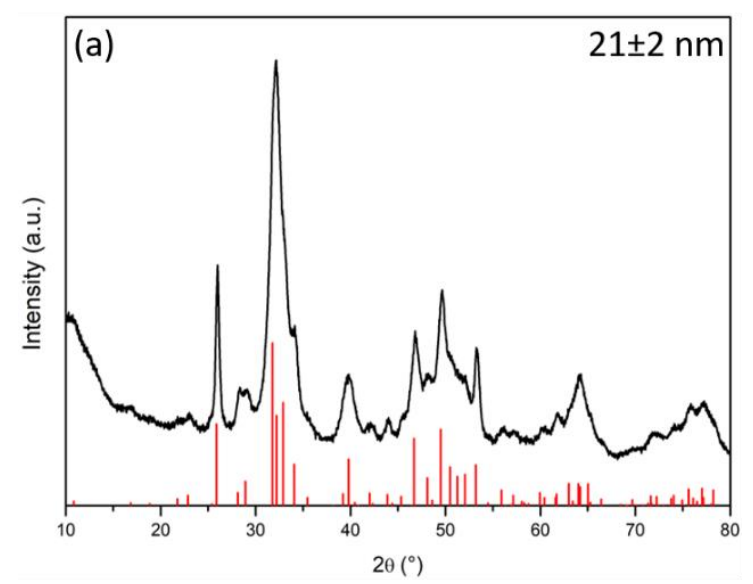

(b)

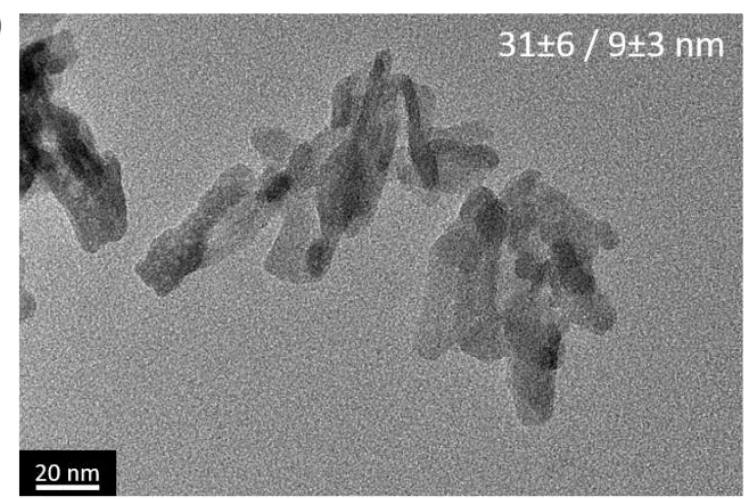

(d)

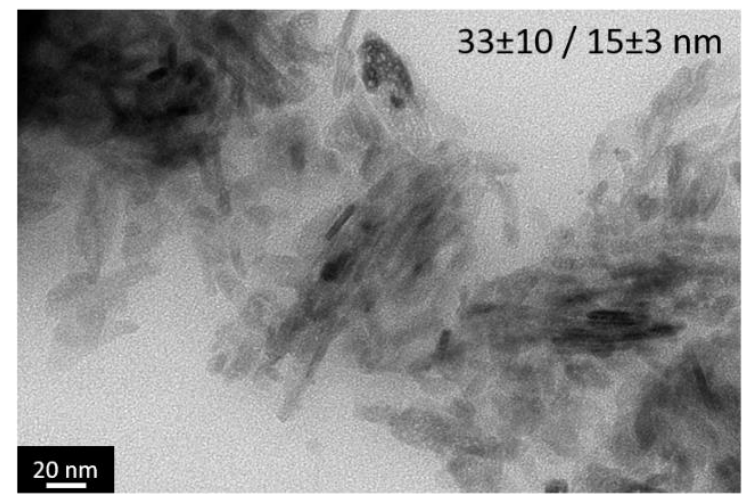

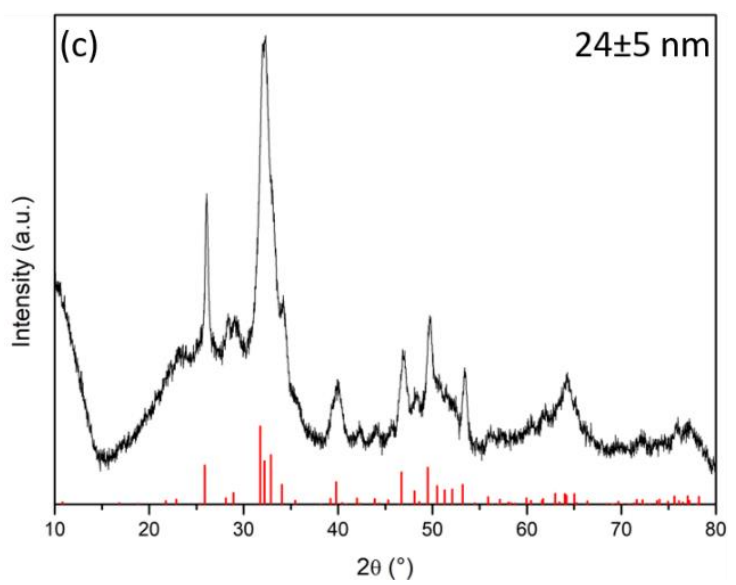

Fig.3 X-ray diffractogram with crystallite size (a,c) and TEM image with average particle dimensions (length/width) (b,d) of hydroxyapatite nanoparticles before (a,b) and after (c,d) baicalein adsorption. 
Baicalein adsorption on the HAp NP was performed over $24 \mathrm{~h}$ in distilled water, at the limit of solubility of BE $(0.05 \mathrm{mM})$. The amount of baicalein on hydroxyapatite nanoparticles was measured by thermogravimetric analysis (TGA), leading to $63 \mathrm{mg} \cdot \mathrm{g}^{-1}$ of baicalein (Supplementary Material, S3). Particle dimensions as observed by TEM and crystallite size as estimated by XRD were not significantly modified by the adsorption process, but particles were more prone to aggregate as observed by TEM (Fig.3b,d).

For further characterization, ${ }^{1} \mathrm{H}$ solid-state NMR experiments were performed on hydroxyapatite nanoparticles before (Fig.4a i)) and after adsorption of baicalein (Fig.4a ii)). Both figures present a superimposition of ${ }^{1} \mathrm{H}$ spectra with probe background suppression (in blue) and with increasing Hahn echo delay (green to brown). This helps to discriminate species by filtering broad peaks having short $\mathrm{T}_{2}$ transversal relaxation. On the spectrum of pure HAp NP, typical signals of protons were evidenced, with a narrow peak at $0 \mathrm{ppm}$ characteristic of isolated protons of hydroxyl group in the crystal lattice, a broader peak at 5.5 ppm characteristic of adsorbed water and a tailing edge up to $17 \mathrm{ppm}$ corresponding to disordered (di)hydrogenophosphates at the HAp surface [48]. After BE adsorption, an asymmetric peak at $7.2 \mathrm{ppm}$ was observed, indicated by a green arrow on Fig.4a ii), corresponding to the aromatic protons of baicalein. Noticeably, water and ethanol peaks strongly decreased, highlighting surface polarity changes.

The ${ }^{1}\left\{{ }^{1} \mathrm{H}\right\}-{ }^{13} \mathrm{C}$ CP spectrum of HAp NP (Fig.4b ii)) was characterized by a broad peak of weak intensity at $170 \mathrm{ppm}$ corresponding to both type $\mathrm{A}$ and $\mathrm{B}$ carbonates, i.e. substitution of hydroxide and phosphate ions, respectively [49]. Carbonates were also visible on the spectrum after adsorption of baicalein (Fig.4b i)). However, the peak is narrower, with a more intense part above $170 \mathrm{ppm}$, which would suggest a type B substitution. In addition, an intense peak at $128 \mathrm{ppm}$ is seen on the spectrum after adsorption of BE. This peak can be assigned to aromatic carbons of baicalein, and confirms the presence of baicalein on the HAp 
NP. Smaller peaks were tentatively attributed to other carbons of the molecule, according to SDBS card 51630 of the parent baicalin molecule. It should be noted that a residual ${ }^{13} \mathrm{C}$ probe signal ranging from 0 to $230 \mathrm{ppm}$ was observed after $14 \mathrm{~h}$ of $\mathrm{CP}$ acquisition of an empty rotor (highlighted in grey on Fig.4b iii)).

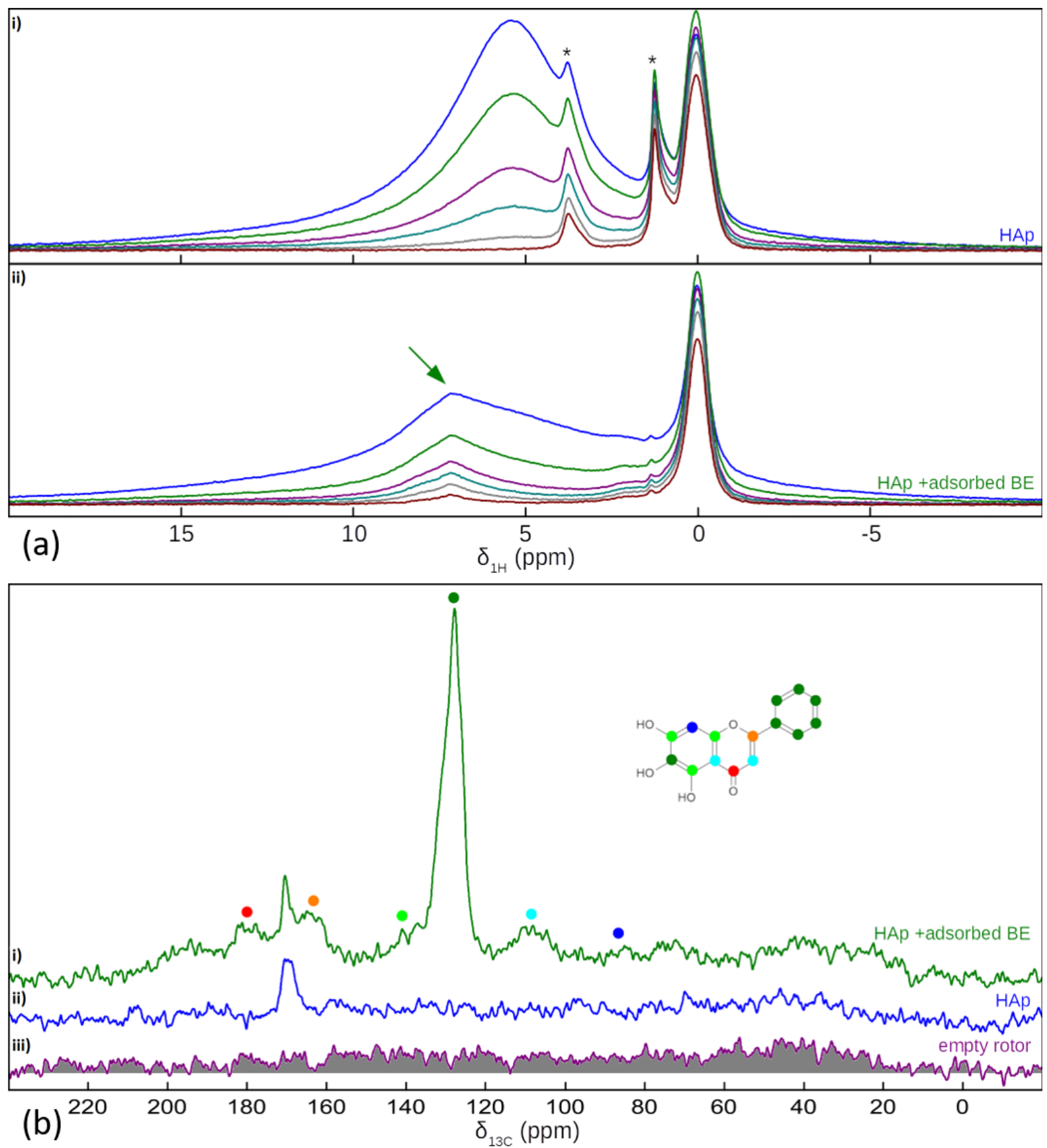

Fig.4 (a) ${ }^{1} \mathrm{H}$ solid-state NMR spectra of pure hydroxyapatite (i) and after adsorption of baicalein (initial concentration for adsorption $=0.05 \mathrm{mM}$ ) (ii). (* indicates residual peaks of washing ethanol); (b) $\left\{{ }^{1} \mathrm{H}\right\}-{ }^{13} \mathrm{C} \mathrm{CP}$ 
solid-state NMR spectra of (i) hydroxyapatite after adsorption of baicalein (initial concentration for adsorption = $0.05 \mathrm{mM}$ ), (ii) pure hydroxyapatite, (iii) empty rotor (positive signal is colored in grey).

2D correlation maps between ${ }^{1} \mathrm{H}$ and ${ }^{31} \mathrm{P}$ of HAp NP were recorded. A contact time of $1 \mathrm{~ms}$ allowed for the observation of both crystalline HAp at $0 \mathrm{ppm}$ for ${ }^{1} \mathrm{H}$ and disordered (di)hydrogenophosphates at the HAp surface up to $17 \mathrm{ppm}$ for ${ }^{1} \mathrm{H}$ (Fig.5a). However, at $10 \mathrm{~ms}$, the combined filtering of $\mathrm{T}_{2}$ relaxation during ${ }^{1} \mathrm{H}$ Hahn echo and $\mathrm{T}_{1 \rho}$ relaxation during $\mathrm{CP}$ almost completely supressed the surface peak, keeping only a small residue at $8.3 \mathrm{ppm}$ (Fig.5b). The same correlation maps were recorded after adsorption of BE. At a contact time of $1 \mathrm{~ms}$, water correlation at $5.5 \mathrm{ppm}$ decreased as compared to HAp NP (Fig.5c). At $10 \mathrm{~ms}$ a new correlation was visible at $7.1 \mathrm{ppm}$ for ${ }^{1} \mathrm{H}$ and $2.7 \mathrm{ppm}$ for ${ }^{31} \mathrm{P}$, corresponding to an interaction between aromatic protons of BE and crystalline phosphates (Fig.5d). This is the sign of the vicinity of BE with HAp NP.

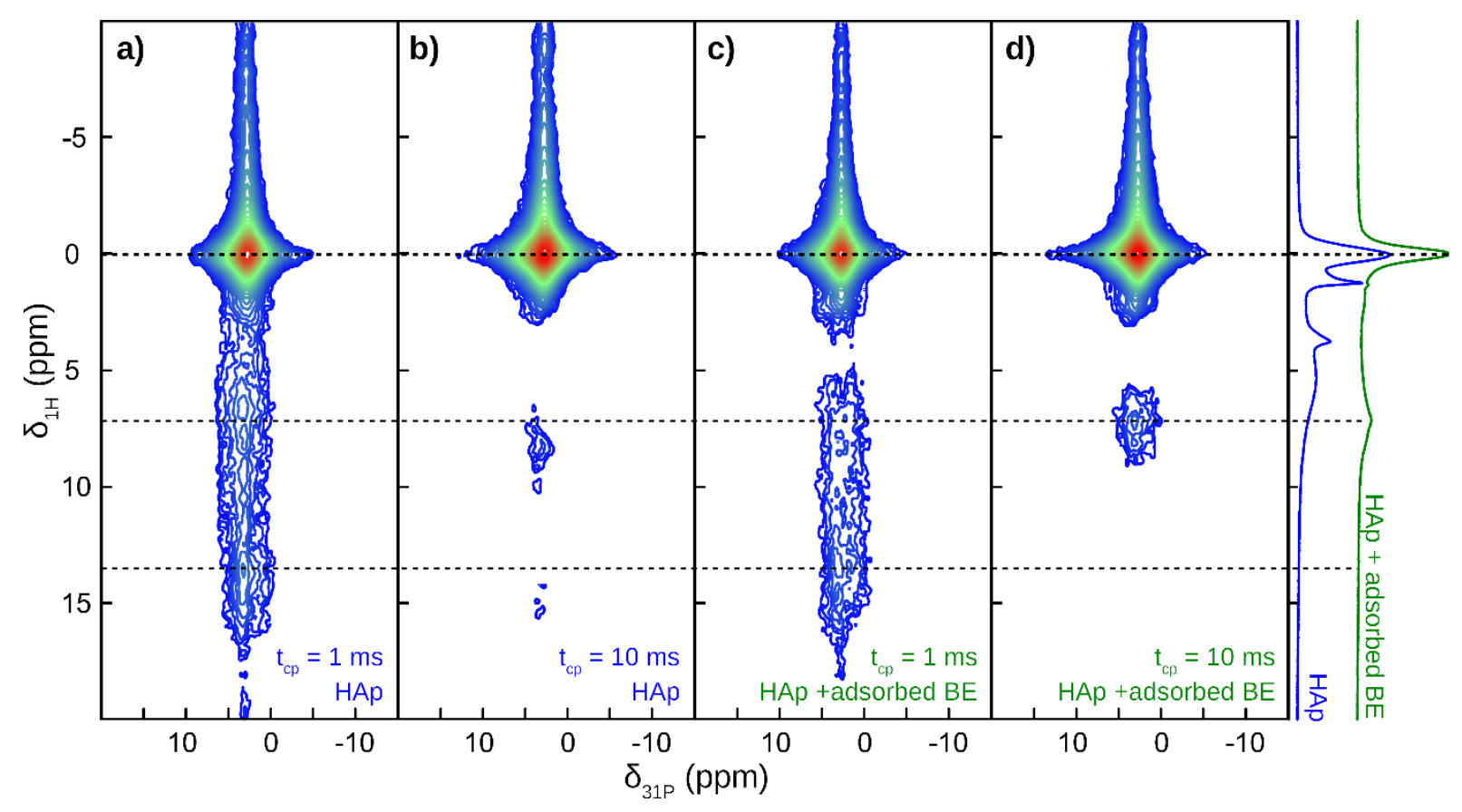

Fig.5 2D T 2 -filtered hetero correlation map ${ }^{1} \mathrm{H}_{-}{ }^{31} \mathrm{P}$ of HAp (a-b) and HAp-BE (c-d) with a contact time of $1 \mathrm{~ms}$ (a,c) and $10 \mathrm{~ms}(\mathrm{~b}, \mathrm{~d})$. Horizontal dashed lines highlight peak positions.

Baicalein release from HAp NPs after adsorption was studied by HPLC. Cumulative release profile of baicalein from NPs, as percentage of the total adsorbed amount, is presented 
in Fig.6. Release profile is characterized by an initial burst, with $20 \%$ of the total amount of adsorbed baicalein released in the first hour. Thereafter, release rate is slower during 24 hours and then a plateau is reached. After 6 days, $40 \%$ of baicalein is released from the hydroxyapatite particles. This suggests that a noticeable amount of baicalein strongly binds to hydroxyapatite.

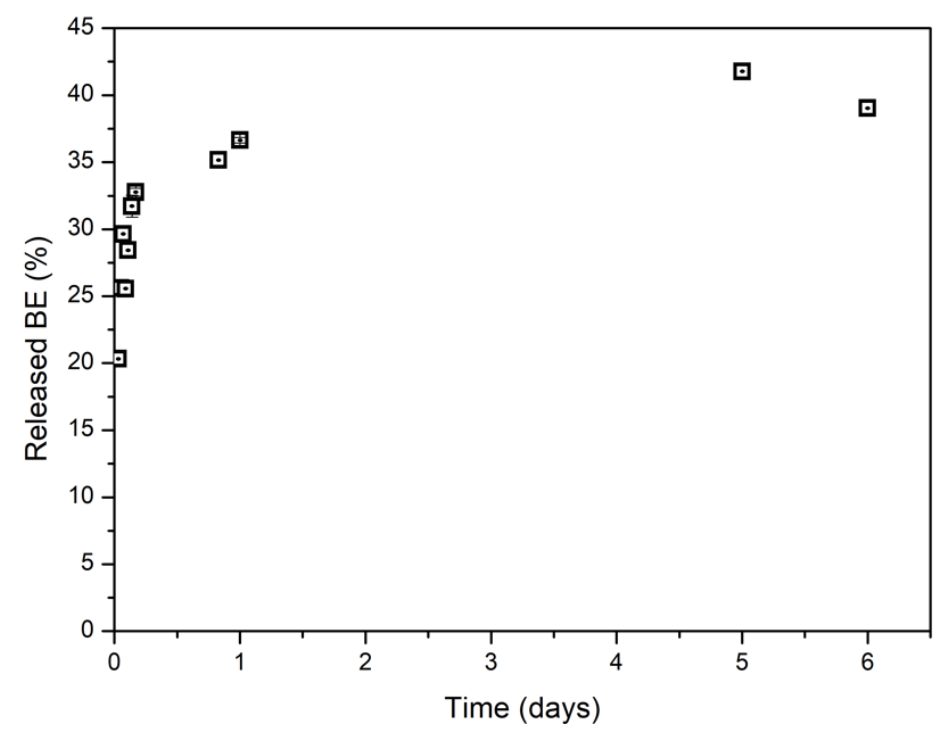

Fig.6 Cumulative release of baicalein with time from nanoparticles.

\subsection{Hydroxyapatite coatings}

A hydroxyapatite coating was deposited on alkaline-treated Ti6Al4V alloy in 1.5-fold concentrated Simulated Body Fluid for 14 days [38,50]. The resulting coating can be described as a dense packing of spheroid-like particles, as observed by SEM on Fig.7. This morphology is typical of HAp coatings deposited from supersaturated solutions [50]. The thickness of the coating, measured after tilting of the sample, is about $12 \mu \mathrm{m}$ (Fig.7c). 

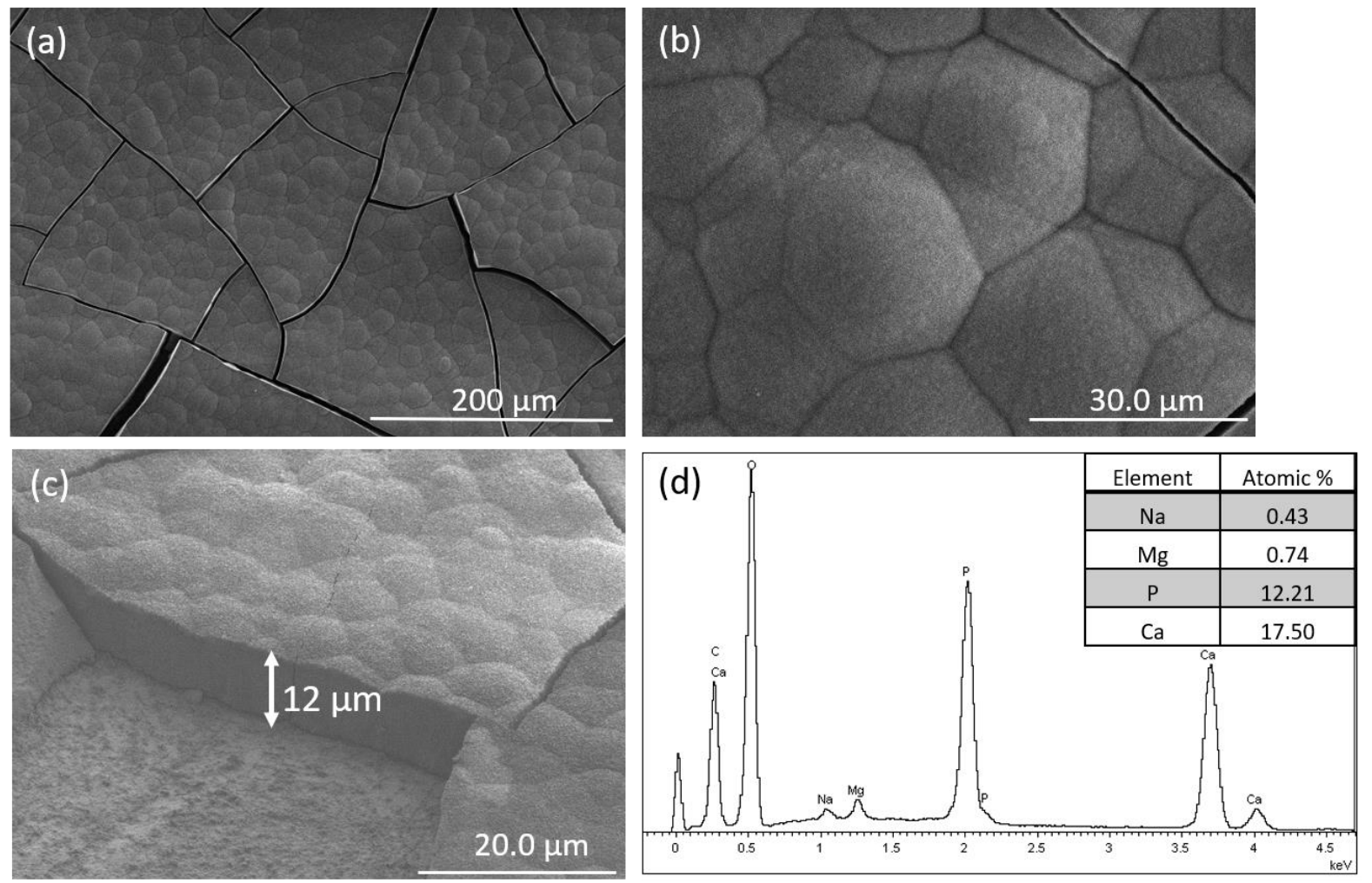

Fig.7 SEM images of Ti6Al4V substrate after 14 days of deposition in 1.5-SBF with tilt $=0{ }^{\circ}(\mathrm{a}, \mathrm{b})$ and $45^{\circ}(\mathrm{c})$; (d) Corresponding EDX spectrum and elemental analysis.

The chemical composition of the HAp layer was assessed by EDX spectroscopy, evidencing the presence of $\mathrm{Ca}, \mathrm{P}, \mathrm{Mg}$ and $\mathrm{Na}$ (Fig.7d). The presence of $\mathrm{Na}$ and $\mathrm{Mg}$ peaks suggests that the HAp layer is substituted. Elemental content was homogeneous over the four analysed zones; the corresponding $\mathrm{Ca} / \mathrm{P}$ ratio is $1.44 \pm 0.02$ and the $(\mathrm{Ca}+\mathrm{Na}+\mathrm{Mg}) / \mathrm{P}$ ratio is $1.54 \pm 0.02$. A stoichiometric hydroxyapatite has a typical $\mathrm{Ca} / \mathrm{P}$ ratio of 1.67 , and, in biological HAp, this ratio is closer to 1.5 due to cationic substitutions [51]. This suggests that the deposited HAp coating is a biomimetic calcium-deficient hydroxyapatite.

Coatings were also characterized by Raman analysis and XRD. As expected, based on the thickness of the HAp coating measured by SEM, the diffraction peaks representative of Ti $\alpha$ and $\beta$ forms (Fig.8a) were the most visible ones on the diffractogram of the coating. However, diffraction peaks representative of hydroxyapatite at $26^{\circ}$ and $32^{\circ}$ were clearly visible on the X-ray diffractogram. The presence of hydroxyapatite was also confirmed by 
Raman analysis (Fig.8b), with the presence of the vibrations representative of phosphate in HAp: $v_{1}$ at $961 \mathrm{~cm}^{-1}, v_{2}$ at $430 \mathrm{~cm}^{-1}, v_{3}$ at $1075 \mathrm{~cm}^{-1}$ and $v_{4}$ at $591 \mathrm{~cm}^{-1}$ [52]. The weak shoulder at $1070 \mathrm{~cm}^{-1}$ may indicate the presence of carbonates in the hydroxyapatite layer [53,54]. Several studies have correlated the full width at maximum half $(\mathrm{FWMH})$ of $v_{1}$ peak at $961 \mathrm{~cm}^{-1}$ with the presence of carbonates in the hydroxyapatite structure: the more the hydroxyapatite is carbonated, the larger the peak is $[55,56]$. In our case, the FWHM is $c a .16$ $\mathrm{cm}^{-1}$. Knowing that non-carbonated crystalline HAp particles have a FWMH below $10 \mathrm{~cm}^{-1}$ [56], this result could be a clue of the presence of carbonated HAp as a coating. However, the broadening of the peak can also be related to the crystallinity of the material [54] and to the substitution of $\mathrm{Ca}^{2+}$ by $\mathrm{Mg}^{2+}$ [57], so that no conclusion can be unambiguously drawn about the coating carbonatation from Raman analysis.

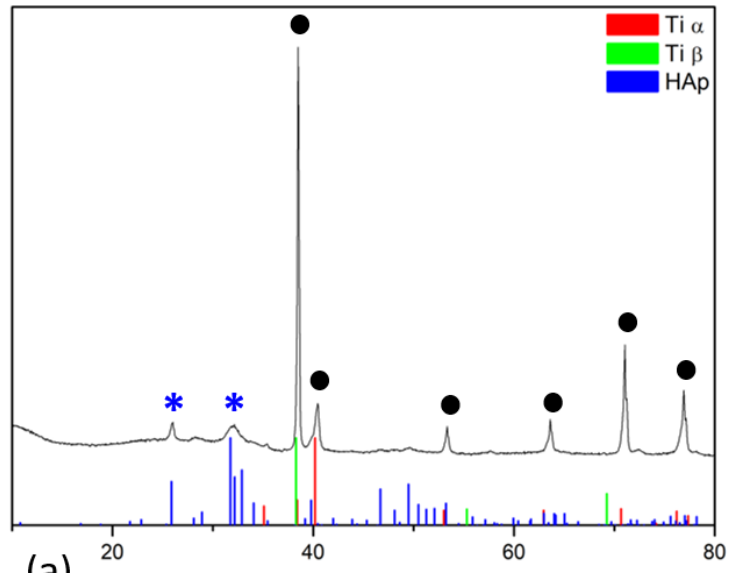

(a) $2 \theta\left({ }^{\circ}\right)$

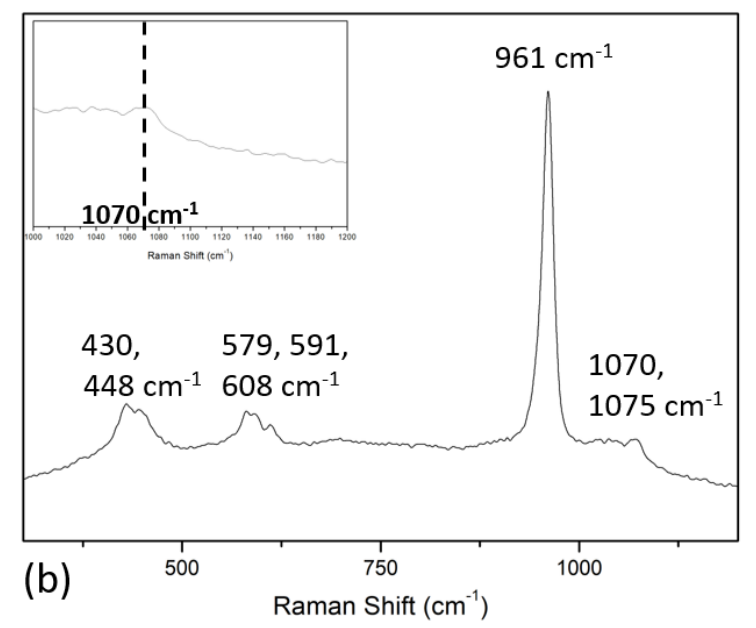

Fig.8 X-ray diffractogram (*: HAp diffraction peaks, $\bullet$ : substrate diffraction peaks) (a) and Raman spectrum (b) of Ti6Al4V substrate after 14 days of deposition in 1.5-SBF (inset: Raman spectrum between 1000 and $1100 \mathrm{~cm}^{-}$ ${ }^{1}$ showing the peak of $\mathrm{CO}_{3}{ }^{2-}$ at $1070 \mathrm{~cm}^{-1}$ )

HAp coatings before and after BE adsorption were also studied by XPS (Fig.9a, b). Oxygen, carbon, calcium, phosphorous, sodium and magnesium were detected on the XPS survey spectrum of bare HAp coating (Fig.9a). Energy and atomic percentages of elements found in the HAp coating are reported in Table $\mathbf{1}$ and compared to literature data for 
stoichiometric HAp (StHAp) [58]. Ca/P ratio in HAp coating was comprised between $1.3 \pm$ 0.12 , thus lower than that of stoichiometric hydroxyapatite (1.67), confirming that the layer is calcium-deficient. More, variable proportions of magnesium and sodium up to $0.4 \%$ were found in the five samples analyzed in this work, thus being consistent with the possible substitution of calcium ions in the upper layer of hydroxyapatite coating. $\mathrm{C}_{1 \mathrm{~s}}, \mathrm{O}_{1 \mathrm{~s}}, \mathrm{Ca}_{2 \mathrm{p}}$ and $\mathrm{P}_{2 p}$ peaks are presented in Fig.9 c-f and their decomposition as Supplementary Material (S4). $\mathrm{C} 1 \mathrm{~s}$ accounts for $c a .15 \%$ of the total atomic percentage of the coating and results from organic adventitious contamination of the inorganic surface [59]. However, the C1s decomposition reveals a contribution -accounting for $9.1 \%$ of the total $\mathrm{C} 1 \mathrm{~s}$ one- at $290.3 \mathrm{eV}$ that can be assigned to metal carbonate [60], thus confirming the carbonatation of the hydroxyapatite coating synthesized in $1.5-\mathrm{SBF}$. $\mathrm{Ca}_{2 \mathrm{p}}$ shows a characteristic doublet of $\mathrm{Ca}$ (II) at $352 \mathrm{eV}$ and at $347 \mathrm{eV}$ due to $\mathrm{Ca}_{2 \mathrm{p} 1 / 2}$ and $\mathrm{Ca}_{2 \mathrm{p} 3 / 2}$, respectively. $\mathrm{P}_{2 \mathrm{p}}$ has closely spaced spinorbit components, resulting in an asymmetric peak envelope. The decomposition clearly shows the $\mathrm{P} 2 \mathrm{p}_{1 / 2}$ and $\mathrm{P} 2 \mathrm{p}_{3 / 2}$ contributions at $134.2 \mathrm{eV}$ and $133 \mathrm{eV}$, respectively. Binding energies for all peaks were similar to those reported for stoichiometric hydroxyapatite [58].

Table 1. Binding energy (eV), atomic percentages (At\%) of carbon, oxygen, calcium, phosphorous, magnesium and sodium and calculated $\mathrm{Ca} / \mathrm{P}$ ratio for bare hydroxyapatite coatings (HAp) and after baicalein sorption (HAp+BE) and comparison with stoichiometric hydroxyapatite (StHAp) [58].

\begin{tabular}{lllllllll}
\hline & Sample & $\mathbf{C}_{1 \mathbf{s}}$ & $\mathbf{O}_{1 \mathbf{s}}$ & $\mathbf{C a}_{2 \mathbf{p} 3 / 2}$ & $\mathbf{P}_{2 \mathbf{p}}$ & $\mathbf{M g}_{1 \mathrm{~s}}$ & $\mathbf{N a}_{1 \mathbf{s}}$ & $\mathbf{C a} / \mathbf{P}$ \\
\hline $\begin{array}{l}\text { Binding } \\
\text { energy } \\
\mathbf{( e V )}\end{array}$ & HAp & $284.9^{*}$ & 530.9 & 346.9 & 132.9 & 1304.2 & 1070.9 & \\
& StHAp[58] & 285.4 & 531.8 & 347.8 & 133.8 & - & - & \\
At\% & HAp & $17 \pm 1$ & $48.4 \pm 1.2$ & $18.5 \pm 1.2$ & $14.5 \pm 1.5$ & $0-0.4$ & $0-0.4$ & $1.3 \pm 0.1$ \\
& HAp + BE & $17 \pm 1$ & $46.1 \pm 0.3$ & $19.6 \pm 0.2$ & $16.5 \pm 0.3$ & b.d. & b.d. & $1.2 \pm 0.1$ \\
& StHAp[58] & - & 59.1 & 22.7 & 13.6 & - & - & 1.67 \\
\hline
\end{tabular}

*carbon from adventitious organic contamination; $b . d .:$ below detection limit 
XPS analysis of the coating after baicalein adsorption showed unchanged element proportions compared to the one before adsorption (Fig. $9 \mathrm{~b}$ and Table 1). Comparison of $\mathrm{C}_{1 \mathrm{~s}}$, $\mathrm{O}_{1 \mathrm{~s}}, \mathrm{Ca}_{2 \mathrm{p}}$ and $\mathrm{P}_{2 \mathrm{p}}$ signal detected in HAp coating before and after BE adsorption are presented in Fig.9 c-f. Only the $\mathrm{C}_{1 \mathrm{~s}}$ spectrum showed a clear envelop modification after BE adsorption. As evidenced on the difference spectrum (Fig.9c), the contributions at $286.4 \mathrm{eV}$, corresponding to $\mathrm{C}-\mathrm{O}-\mathrm{C}$ and/or $\mathrm{C}-\mathrm{O}-\mathrm{H}$ bonds and the one at $288.5 \mathrm{eV}$, corresponding to $\mathrm{C}=\mathrm{O}$, are higher after adsorption of baicalein: $10.5 \%$ to $23.6 \%$ and $13.3 \%$ to $16.8 \%$, respectively. 

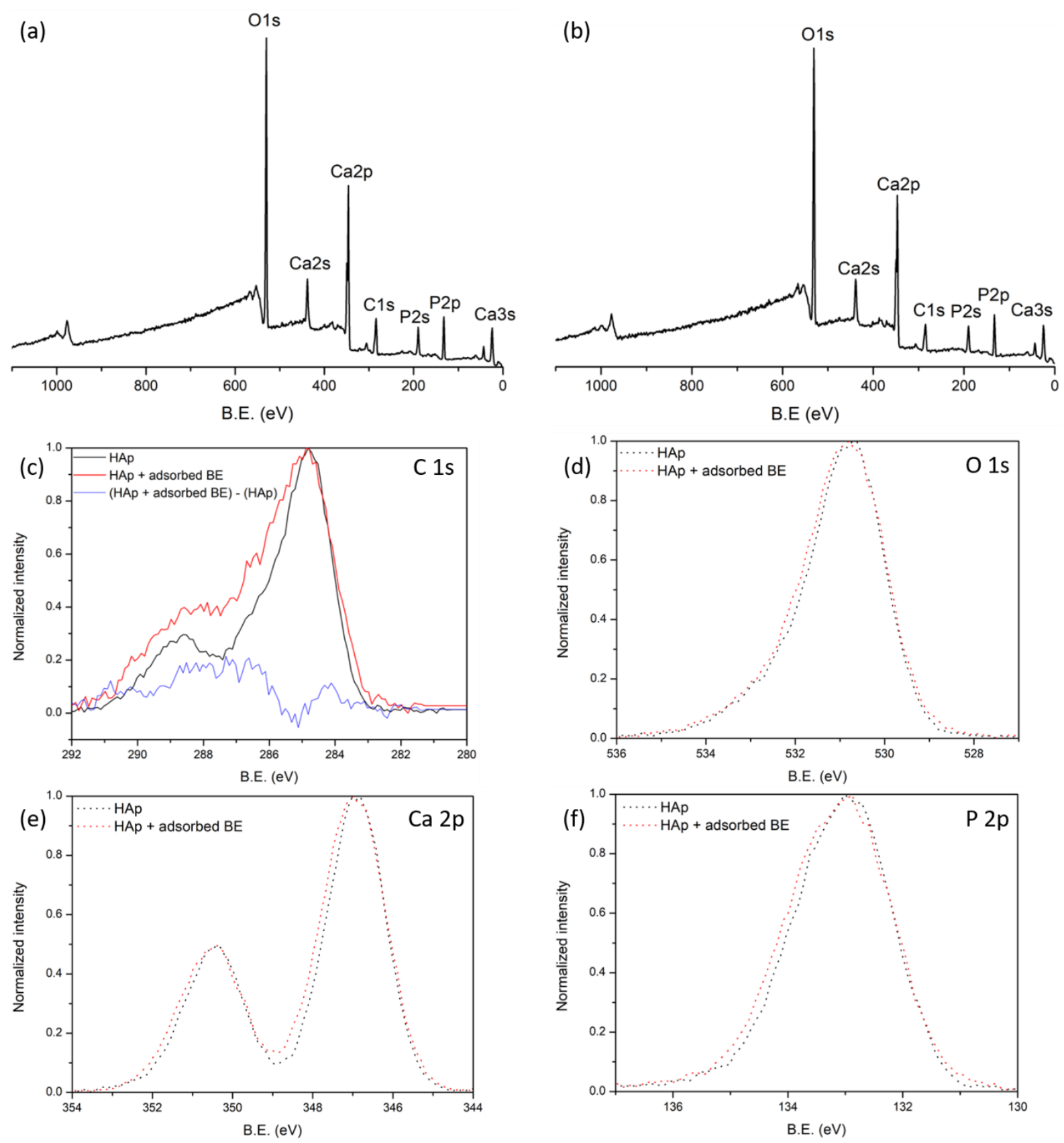

Fig.9 XPS survey spectrum of HAp coating before (a) and after (b) adsorption of baicalein; comparison of XPS spectra of $\mathrm{C}_{1 \mathrm{~s}}(\mathrm{c}), \mathrm{O}_{1 \mathrm{~s}}(\mathrm{~d}), \mathrm{Ca}_{2 \mathrm{p}}(\mathrm{e})$ and $\mathrm{P}_{2 \mathrm{p}}(\mathrm{f})$ of HAp coating before and after adsorption of baicalein.

This result could indicate the presence of BE in the HAp coating. However, it is worth noticing that a potential adsorption of BE on HAp cannot unambiguously be evidenced from XPS data since BE is composed of only $\mathrm{C}, \mathrm{O}$ and $\mathrm{H}$ atoms and all these elements are already 
present on bare HAp XP spectrum because of the presence of adventitious contamination whose proportion is indeed uncontrolled.

Fluorescence spectra of the coating were also studied. Under excitation at $300 \mathrm{~nm}$, HAp coating on titanium alloy exhibited an emission spectrum with a band with a maximum at $395 \mathrm{~nm}$, as seen on Fig.10. The latter signal was also observed as a slight shoulder on the spectrum of HAp + BE. Because the HAp band gap ranges between 5.58 and $5.78 \mathrm{eV}$ [61], this material is transparent for wavelengths higher than $222 \mathrm{~nm}$. Consequently, the signal cannot be assigned to HAp. However, a broad photoluminescence spectrum has already be reported, with emitted light wavelength in the range of $400-450 \mathrm{~nm}$ as a results of defects in the crystal lattice and/or of the presence of some impurities as $\mathrm{CO}_{2}{ }^{--}$radicals resulting from the bond cleavages and trapped by the already formed hydroxyapatite lattice or interstitial positions $[62,63] . \mathrm{CO}_{3}{ }^{2-}$ substituting for $\mathrm{OH}$ groups and its decomposition could also contribute to the appearance of additional energy levels [61]. The observed emission peak at $\sim 395 \mathrm{eV}$ can also be due to the recombination of photogenerated electron-hole pairs as it corresponds to optical band gap of anatase titania $(\sim 3.2 \mathrm{eV})$ formed as a surface layer after titanium alloy basic treatment. In the presence of $\mathrm{BE}$, an additional broad peak is evidenced on the HAp coated alloy with a maximum at $518 \mathrm{~nm}$. As a comparison, the fluorescence spectra of baicalein in solution measured in DMSO at the same excitation wavelength exhibits a peak $540 \mathrm{~nm}$ (Supplementary Material, S5). It therefore seems reasonable to attribute the $518 \mathrm{~nm}$ peak of the HAP+BE coating to baicalein, the wavelength shift being attributed to the modification of the environment of the molecule on the hydroxyapatite surface compared to DMSO.

Attempts were made to determine the amount of adsorbed BE on the HAp coating by microthermogravimetry analysis. Measurements have been carried out in a microthermogravimetric apparatus (Hiden Isochema IGA-003) enabling the mass changes 
samples to be determined as a function of time with the accuracy lower than $2.10^{-7} \mathrm{~g}$. Assuming that all the BE present in the soaking solution has been adsorbed, the HAp coating could contain up to $5.5 \times 10^{-5} \mathrm{~g}$ of baicalein, that is higher than the TG device sensitivity. It could therefore be expected to detect some BE on the HAp. However, no significant variation in the mass loss curve could be detected when increasing the temperature of a HAp+BE sample from $20^{\circ} \mathrm{C}$ to $500{ }^{\circ} \mathrm{C}$ (Supplementary Material, S6). The low amount of adsorbed BE is also confirmed by the absence of peaks attributable to baicalein on the FTIR spectrum of the HAp+BE coating, only the bands at $1031 \mathrm{~cm}^{-1}$ and $1062 \mathrm{~cm}^{-1}$, indicative of HAp formation, being observed before and after adsorption (Supplementary Material, S7).

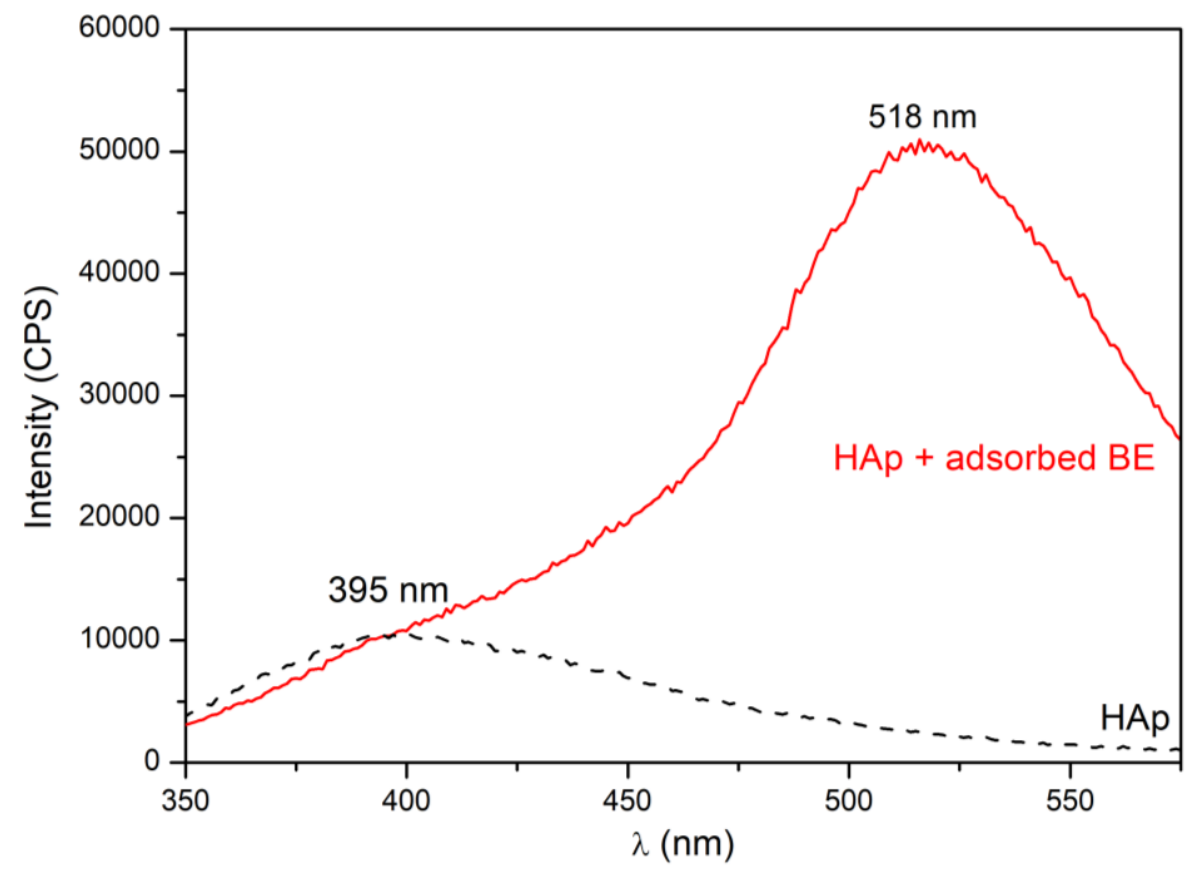

Fig.10 Fluorescence spectra of hydroxyapatite coatings before and after adsorption of baicalein at $\lambda_{\mathrm{ex}}=300 \mathrm{~nm}$ 
SEM images of hydroxyapatite coating after adsorption are presented in Fig.11a. Two different layers could be evidenced: a lower dense and homogeneous one that looks like flattened and joined spheroids and an upper one with a cauliflower structure non-uniformly covering the lower layer. This would suggest that part of the hydroxyapatite coating was dissolved and/or remodeled during the adsorption process. To check whether this modification of the upper surface morphology is linked to the presence of $\mathrm{BE}$ or to the immersion of the coating, a HAp coating was dipped in water for 24 hours. The resulting SEM images show a dense layer of spheroids (Fig. 11b), reminiscent of the layer before immersion, as seen on Fig.6, but less dense and homogeneous. Therefore, it seems that both water immersion and BE adsorption can impact on the surface morphology of the coatings, with a greater effect in the case of BE adsorption. 

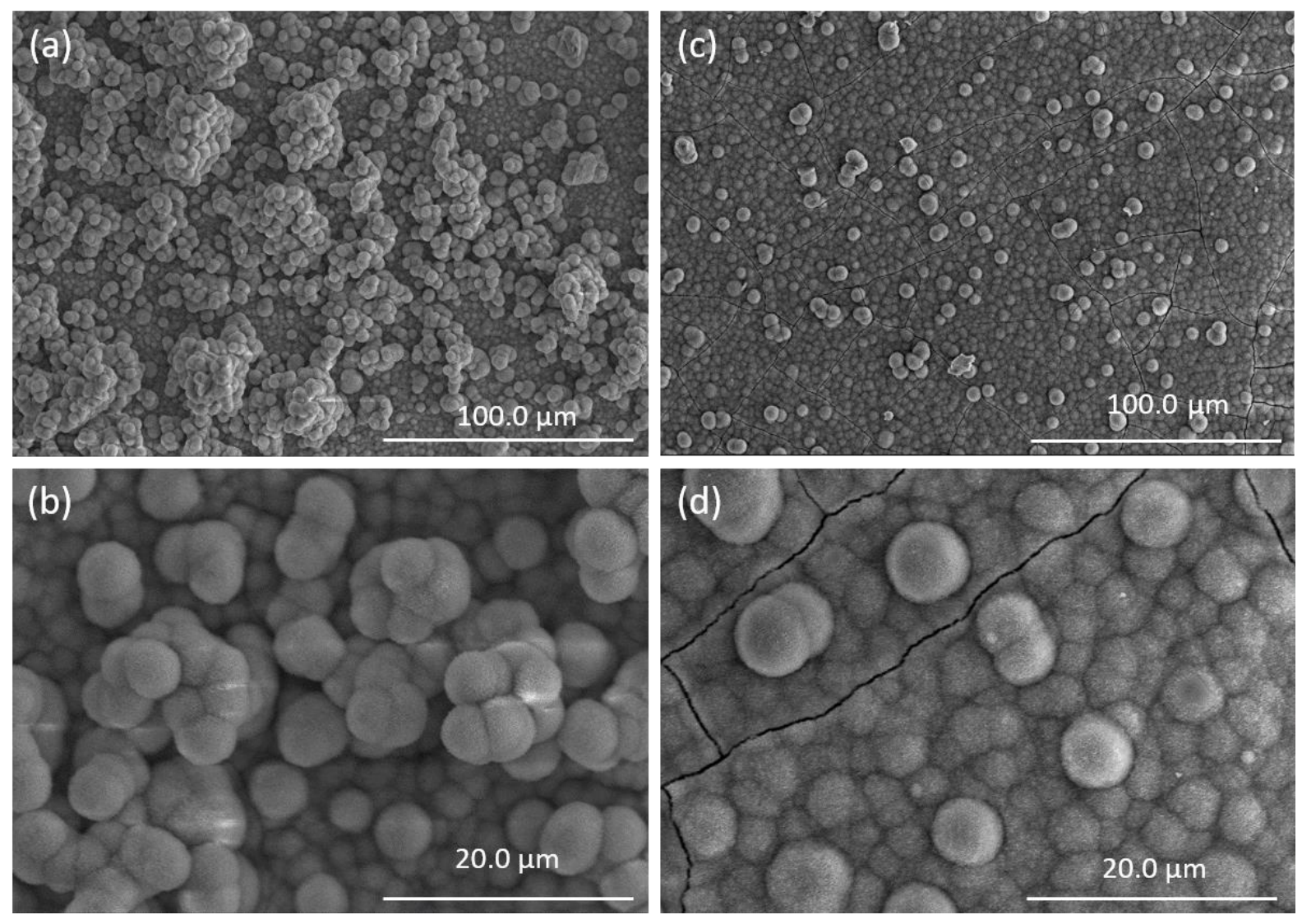

Fig.11 SEM images of HAp coating after baicalein adsorption $(a, b)$ and after immersion in water for 24 hours (c,d). Magnification: x500 (a,c) and x2.5 k (b,d)

\subsection{Antibacterial and antioxidant activities}

\subsubsection{Antibacterial activity}

Antibacterial activity of baicalein in solution was tested against S. epidermidis CIP 105.777, a strain being capable of forming biofilms. The minimum inhibitory concentration (MIC) of baicalein was $34 \mu \mathrm{g} \cdot \mathrm{mL}^{-1}$, which corresponds to $126 \mu \mathrm{mol} \cdot \mathrm{L}^{-1}$.

The antibacterial activity of HAp NPs was tested in liquid medium against S. epidermidis CIP 105.777 in $\mathrm{MH}$ culture broth for 16 hours at $37{ }^{\circ} \mathrm{C}$ (Fig.12a). Two concentrations of HAp NPs were tested: $5 \mathrm{mg} \cdot \mathrm{mL}^{-1}$ and $25 \mathrm{mg} \cdot \mathrm{mL}^{-1}$. The number of living bacteria in contact with particles counted after 24 hours was identical (within the experimental error) for NP and NP+BE. 


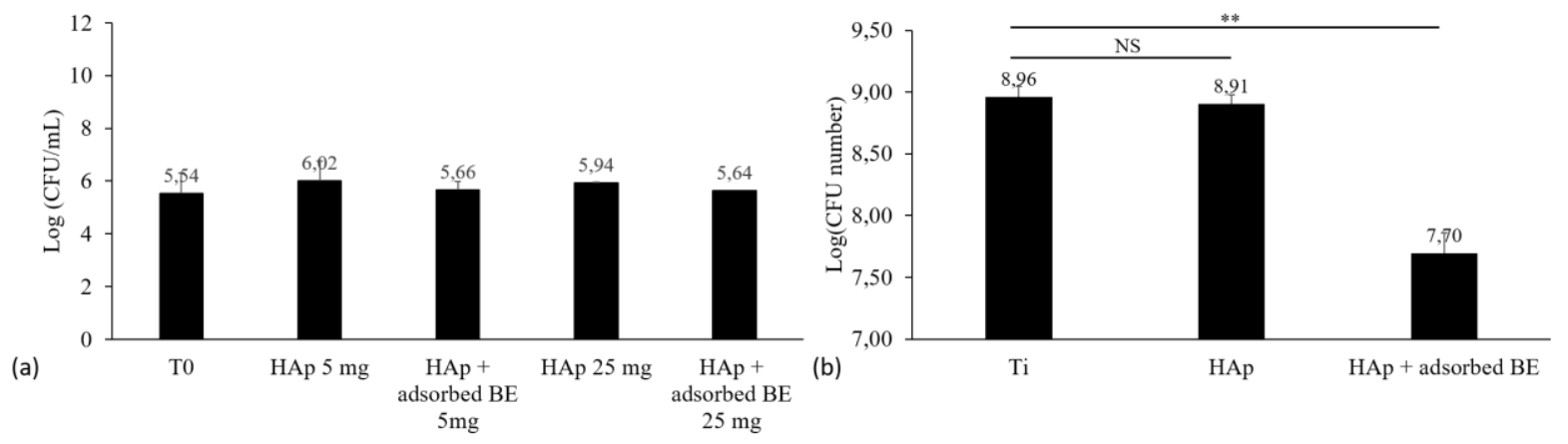

Fig.12. (a) Antibacterial activity of pure HAp nanoparticles and particles after adsorption of baicalein against $S$. epidermidis CIP 105.777 (T0 is the bacterial density at the beginning of the experiment); (b) Antibacterial activity of pure HAp coatings and coatings after adsorption of baicalein against S. epidermidis CIP 105.777 (NS: non-significant, $* *: \mathrm{p} \leq 0.01)$

The antibacterial activity of hydroxyapatite coating was tested against S. epidermidis CIP 105.777, MH culture broth for 16 hours at $37{ }^{\circ} \mathrm{C}$. The number of bacteria alive after 16 hours incubation is shown in Fig. 12b. In the presence of bare Ti substrate and HAp coated Ti, these numbers were identical, i.e. $9.1 \times 10^{8} \mathrm{CFU} \cdot \mathrm{mL}^{-1}$. However, the bacterial growth was reduced by one order of magnitude on the HAp + BE surface compared to HAp coating with $5.0 \times 10^{7}$ CFU.mL ${ }^{-1}$. This decrease of bacterial growth is significant, with a $p$ value calculated with Student's t-test of 0.008 .

The comparison of the results obtained with NPs and coating probably highlights the effect of different surface properties. Indeed, while bacteria are expected to have only local interactions with nanoscale particles, they can firmly adhere on the extended surface of the coatings, all the more as SEM shows that they exhibit a significant roughness. Such a tight interaction could favour the antibacterial effect of adsorbed BE.

\subsubsection{Antioxidant activity}

Due to its phenolic structure, baicalein develops antioxidant activity that was studied by Blois method $[46,47]$. Antioxidant activity of HAp NP and HAp-coated Ti was expressed as a percentage of the DPPH absorption reduction, after 20 min of reaction in the dark. As a 
comparison, the activity of a $0.1 \mathrm{mM}$ solution of BE in TRIS buffer was also tested, and results are gathered in Table 2 . The antioxidant activity of $0.1 \mathrm{mM}$ baicalein in solution is 36 $\%$ at $\mathrm{pH}$ 7.4. Bare HAp NPs did not exhibit any antioxidant activity. (BE + HAp) NPs exhibited $70 \%$ of antioxidant activity. After 1 and 5 days in suspension, the activity was $c a$. $50 \%$, which can be related to the concomitant release of $c a .40 \%$ of BE over this period (Fig.6). In contrast, HAp-coated Ti with adsorbed baicalein had a non-zero but very small one ( $2 \%)$. Such a low antioxidant activity is however in line with what could be expected on the basis of the maximal amount of adsorbed BE, i.e $2.10^{-7}$ moles.

Table 2. Antioxidant activity expressed as DPPH bleaching percentage of baicalein ( $0.1 \mathrm{mM}$ in Tris buffer), hydroxyapatite nanoparticles $(10 \mathrm{mg}$ ) and coatings before and after adsorption of baicalein.

\begin{tabular}{llc}
\hline Sample & & $\begin{array}{c}\text { DPPH absorbance } \\
\text { reduction } \\
(\boldsymbol{\%})\end{array}$ \\
\hline $0.1 \mathrm{mM}$ baicalein & 36 \\
HAp alone & Nanoparticles & 0 \\
& Coatings & 0 \\
HAp $+\mathrm{BE}$ & Nanoparticles & $70 \pm 11$ \\
& Coatings & $2 \pm 1$ \\
\hline
\end{tabular}

\section{Discussion}

\subsection{Adsorption of baicalein on hydroxyapatite nanoparticles and coatings}

Baicalein was successfully adsorbed on hydroxyapatite nanoparticles to an extent of $63 \mathrm{mg} \cdot \mathrm{g}^{-1}$. The presence of baicalein was confirmed by ${ }^{1} \mathrm{H},{ }^{13} \mathrm{C}$ and ${ }^{31} \mathrm{P}$ solid state NMR spectroscopy. Adsorption of baicalein did not modify the morphology nor crystallinity of HAp NPs, as observed by TEM and XRD. In case of coating of Ti alloy plates with HAp synthesized in 1.5-SBF, the presence of adsorbed BE was evidenced by fluorescence measurements and, to some extent, by a modification of the XPS $\mathrm{C}_{1 \mathrm{~s}}$ peak. Moreover, the fact that significant antioxidant activity is observed for (BE+HAp)-coated plates and not for Hap- 
coated ones support baicalein adsorption. However, the amount of adsorbed BE was too low to be quantified by thermogravimetry, i.e. below $1.4 \mathrm{mg}$ per $\mathrm{g}$ of HAp on the basis of the detection limit of the used thermobalance.

Three kinds of interactions are likely to take place between adsorbed BE and the hydroxyapatite surface: (1) electrostatic, (2) hydrophilic (hydrogen bond)/hydrophobic and (3) complexation with the calcium ions [64-66]. The first two are highly correlated to the surface charge of HAp: at $\mathrm{pH}$ below its isoelectric point (IEP), the surface is positivelycharged and has good affinity for anionic species, while the mirror situation occurs at $\mathrm{pH}$ above IEP. Near the IEP, the HAp surface has a marked hydrophobic character. The IEP of hydroxyapatite can range between 7 and 8 [67], being therefore positively-charged in the sorption conditions in this work $(\mathrm{pH} 5)$, whereas baicalein is neutral at this $\mathrm{pH}$. Here the significant affinity of BE for the hydroxyapatite surface can be interpreted in light of a study by Chirdon et al.[68] showing that catechol and pyrogallol adsorbed readily and strongly on HAp surfaces. The proposed explanation is based on cooperative hydrogen-bond interactions thanks to the presence of two or three close phenol groups. It is well-documented that organic molecules, such as catechols, that have strong affinity for mineral surfaces can accelerate their dissolution $[69,70]$. Thus, it can be suggested that BE is able to complex calcium on the HAp surface and dissolve it to release $\mathrm{Ca}-\mathrm{BE}$ species. This would increase the relative amount of $\mathrm{P}$, in agreement with the XPS data. The reason why this would occur for coatings and not for nanoparticles may be related to the difference in crystallinity of the samples.

\subsection{Antioxidant and antibacterial activities}

Antioxidant properties of baicalein, as characterized by the DPPH radical scavenging assay, was $36 \%$ at a concentration of $0.1 \mathrm{mM}$ in Tris buffer. After adsorption on HAp nanoparticles, the molecule kept its activity: HAp NP with adsorbed BE had an antioxidant 
activity of $70 \%$. It is important to point out that, in the conditions of the DPPH test with 10 $\mathrm{mg}$ of HAp+BE nanoparticles in $1 \mathrm{~mL}$, baicalein concentration is $c a .2 \mathrm{mM}$. This value is higher than that tested for baicalein in solution $(0.1 \mathrm{mM})$, which can contribute to the highest antioxidant activity. As a matter of fact, such a $2 \mathrm{mM}$ concentration is larger than the solubility limit of $\mathrm{BE}$ in water, evidencing the benefit of its association with the HAp nanoparticles. Recently, hydroxyapatite nanoparticles modified with catechin, another flavonoid, also demonstrated higher antioxidant activity for the surface-immobilized molecules compared to the soluble form, attributed to the high surface density of the active molecules [71]. In contrast to nanoparticles, the activity of here-obtained coatings after adsorption was very low. This result may be explained by an adsorbed quantity of baicalein on coatings that is not sufficient to exhibit a measurable antioxidant activity against DPPH radical.

As far as the antibacterial activity is concerned, (HAp NP $+\mathrm{BE})$ were not bactericidal against S. epidermidis CIP 105.777. This contrasts with other drug-release hydroxyapatite nanoparticles reported in the literature [72-76]. For instance, porous hydroxyapatite nanoparticles loaded with tetracycline, a broad-spectrum antibiotic, was shown to inhibit Escherichia coli growth in 2 hours, and remained active for several days [74]. Antibacterial activity was tested following the disk diffusion method, with particles shaped as pellets. This antimicrobial testing method was also used to evaluate the activity of hydroxyapatite nanoparticles loaded with vancomycin, against laboratory strains of S. aureus and E. coli, and MRSA [73]. Particles were active for 7 days against MRSA, and for more than 20 days against the other strains. In the first example, a drug loading similar to our system was achieved, while in the latter one, much higher amounts of antibiotics (160 mg.g $\left.{ }^{-1}\right)$ were immobilized. Thus, the difference of activity between these systems and ours should be strongly linked to the intrinsic antibacterial activity of the used molecules. These studies 
described hydroxyapatite loading with classic broad-spectrum antibiotic (vancomycin and tetracyclin), with MIC much below that of baicalein (MIC $<1 \mu \mathrm{g} \cdot \mathrm{mL}^{-1}$ compared to 34 $\mu \mathrm{g} \cdot \mathrm{mL}^{-1}$ for $\left.\mathrm{BE}\right)$.

Quite surprisingly, a small but significant antibacterial activity was measured for hydroxyapatite coatings with adsorbed baicalein against S. epidermidis CIP 105.777 in rich medium, despite the low drug loading. The bacterial growth was reduced by one order of magnitude in presence of baicalein compared to titanium alloy substrate or pure hydroxyapatite coatings. Noticeably, preliminary cytotoxicity assays using fibroblasts did not evidence any harmful effect for baicalein solution of concentrations up to $50 \mu \mathrm{g} \cdot \mathrm{mL}^{-1}$ (Supplementary Material, S8). Such a concentration is very unlikely to be reached in vivo considering that $\mathrm{BE}$ loading on coatings is maximum $25 \mu \mathrm{g}$ per $\mathrm{cm}^{2}$ of coating. This suggests that the presence of BE should not impact the biocompatibility of the implant. Again, this activity is lower than the activity of other calcium phosphate coatings incorporating antibiotics reported in the literature. For example hydroxyapatite coatings with adsorbed tobramycin or cephalothin are effective against $S$. aureus in $16 \mathrm{~h} \mathrm{[15].} \mathrm{Tobramycin} \mathrm{was} \mathrm{also}$ adsorbed on phosphate calcium coating on fixation pins, with a sustained antibacterial activity for 7 days, despite an initial burst release in 15 min [23]. However, the comparison of antibacterial activity results was not obvious, because the method of testing, in solid medium on agar plates, was different from the one we used (test in solution). Yet, the major difference between these coatings and ours was again the antibacterial activity of the antibiotics alone.

The question is raised why, despite a lower BE loading, coatings showed some antibacterial activity whereas nanoparticles did not. One plausible reason is that the area of contact between the bacteria and the modified surface is larger on the flat coating compared to the curved nanoparticles, which should be more favorable towards biofilm-forming bacteria. 


\section{Conclusions}

With the aim of developing new coatings for metallic implants that would combine bioactivity and antibacterial properties, we have associated hydroxyapatite, in a nanoparticulate and a coating form, with baicalein, a natural antibacterial compound. Nanoparticles have the advantages of easy preparation and high antibiotic loading but showed no antibacterial activity in the conditions of this work. Nevertheless, it is possible to take advantage of another property of baicalein, its antioxidant activity, to design nanoparticles with higher efficiency than the molecule alone. As a comparison, hydroxyapatite coatings exhibiting a biomimetic composition, i.e. calcium-deficient carbonated hydroxyapatite, showed a significant although low antibacterial activity, despite a low amount of adsorbed baicalein (below $1 \mathrm{wt} \%$ ).

Overall, the antibacterial performances of the material studied in this work are below that of related systems in the literature using current synthetic antibiotics. One of the main reasons is that such synthetic antibiotics are at least 100 times more active (i.e. have MIC two orders of magnitude smaller) than natural antibacterial molecules on susceptible strains. This issue is more problematic here as the concentration of the solution that can be used for baicalein adsorption is limited by the poor solubility of BE in water $(0.1 \mathrm{mM})$. Nevertheless, the choice of active molecules from traditional medicine remains a promising solution to address current concern raised by the rapidly developing phenomenon of antibiotic resistance. Improvement of baicalein loading may be possible if porous hydroxyapatite nanoparticles or coatings are used. Moreover, in traditional medicine, plant extracts containing several antibacterial molecules acting synergistically are used instead of single molecules. Thus, associating more complex natural formulations, such as essential oils, with hydroxyapatite could be a highly relevant strategy for the future. 
Funding: This work was supported by French state funds within the framework of the Cluster of Excellence MATISSE led by Sorbonne Université, by the PICS program of CNRS and by PHC PROCORE project $n^{\circ} 37681$ XE funded by the French Ministry of Foreign Affairs.

\section{Acknowledgments}

The authors thank Gervaise Mosser and Patrick Le Griel from LCMCP for technical assistance. 


\section{References}

[1] S.M. Kurtz, K.L. Ong, J. Schmier, K. Zhao, F. Mowat, E. Lau, Primary and Revision Arthroplasty Surgery Caseloads in the United States from 1990 to 2004, The Journal of Arthroplasty. 24 (2009) 195-203. https://doi.org/10.1016/j.arth.2007.11.015.

[2] B. Zhang, D. Myers, G. Wallace, M. Brandt, P. Choong, Bioactive Coatings for Orthopaedic Implants - Recent Trends in Development of Implant Coatings, International Journal of Molecular Sciences. 15 (2014) 11878-11921. https://doi.org/10.3390/ijms150711878.

[3] M. Kaur, K. Singh, Review on titanium and titanium based alloys as biomaterials for orthopaedic applications, Materials Science and Engineering: C. 102 (2019) 844-862. https://doi.org/10.1016/j.msec.2019.04.064.

[4] K. Anselme, M. Bigerelle, Topography effects of pure titanium substrates on human osteoblast long-term adhesion, Acta Biomaterialia. 1 (2005) 211-222. https://doi.org/10.1016/j.actbio.2004.11.009.

[5] D.D. Deligianni, N. Katsala, S. Ladas, D. Sotiropoulou, J. Amedee, Y.F. Missirlis, Effect of surface roughness of the titanium alloy Ti-6Al-4V on human bone marrow cell response and on protein adsorption, Biomaterials. 22 (2001) 1241. https://doi.orh/10.1016/s0142-9612(00)00274$\mathrm{x}$.

[6] E. Chikarakara, P. Fitzpatrick, E. Moore, T. Levingstone, L. Grehan, C. Higginbotham, M. Vázquez, K. Bagga, S. Naher, D. Brabazon, In vitro fibroblast and pre-osteoblastic cellular responses on laser surface modified Ti-6Al-4V, Biomedical Materials. 10 (2014) 015007. https://doi.org/10.1088/1748-6041/10/1/015007.

[7] J. Li, I. Mutreja, S. Tredinnick, M. Jermy, G.J. Hooper, T.B.F. Woodfield, Hydrodynamic control of titania nanotube formation on Ti-6Al-4V alloys enhances osteogenic differentiation of human mesenchymal stromal cells, Materials Science and Engineering: C. 109 (2020) 110562. https://doi.org/10.1016/j.msec.2019.110562.

[8] H. Qiao, G. Song, Y. Huang, H. Yang, S. Han, X. Zhang, Z. Wang, J. Ma, X. Bu, L. Fu, Si, Sr, $\mathrm{Ag}$ co-doped hydroxyapatite/ $\mathrm{TiO}_{2}$ coating: enhancement of its antibacterial activity and osteoinductivity, RSC Advances 9 (2019) 13348-13364. https://doi.org/10.1039/C9RA01168D.

[9] H. Qiao, Q. Zou, C. Yuan, X. Zhang, S. Han, Z. Wang, X. Bu, H. Tang, Y. Huang, Composite coatings of lanthanum-doped fluor-hydroxyapatite and a layer of strontium titanate nanotubes: fabrication, bio-corrosion resistance, cytocompatibility and osteogenic differentiation, Ceramics International. 44 (2018) 16632-16646. https://doi.org/10.1016/j.ceramint.2018.06.090.

[10] M. Kazemi, S. Ahangarani, M. Esmailian, A. Shanaghi, Investigation on the corrosion behavior and biocompatibility of Ti-6Al-4V implant coated with HA/TiN dual layer for medical applications, Surface and Coatings Technology. 397 (2020) 126044. https://doi.org/10.1016/j.surfcoat.2020.126044.

[11] Q. Yao, Y. Jiang, S. Tan, X. Fu, B. Li, L. Liu, Composition and bioactivity of calcium phosphate coatings on anodic oxide nanotubes formed on pure Ti and Ti-6Al-4V alloy substrates, Materials Science and Engineering: C. 110 (2020) 110687. https://doi.org/10.1016/j.msec.2020.110687.

[12] T. late T. Kitsugi, T. Yamamuro, T. Nakamura, M. Oka, Transmission electron microscopy observations at the interface of bone and four types of calcium phosphate ceramics with different calcium/phosphorus molar ratios, Biomaterials. 16 (1995) 1101-1107. https://doi.org/10.1016/0142-9612(95)98907-V.

[13] D.S.M.G. Kruijntjens, P. Kjaersgaard-Andersen, P. Revald, J.S. Leonhardt, J.J.C. Arts, R.H.M. ten Broeke, 5-year clinical and radiographic follow-up of the uncemented Symax hip stem in an international study, Journal of Orthopaedic Surgery Research. 13 (2018) 191. https://doi.org/10.1186/s13018-018-0888-9.

[14] T.J. Wood, M. Alzahrani, J.D. Marsh, L.E. Somerville, E.M. Vasarhelyi, B.A. Lanting, Use of the Corail stem for revision total hip arthroplasty: evaluation of clinical outcomes and cost, canadian Journal of Surgery. 62 (2019) 78-82. https://doi.org/10.1503/cjs.002318.

[15] M. Stigter, J. Bezemer, K. de Groot, P. Layrolle, Incorporation of different antibiotics into carbonated hydroxyapatite coatings on titanium implants, release and antibiotic efficacy, Journal of Controlled Release. 99 (2004) 127-137. https://doi.org/10.1016/j.jconrel.2004.06.011. 
[16] K. Zawisza, P. Sobierajska, N. Nowak, A. Kedziora, K. Korzekwa, B. Pozniak, M. Tikhomirov, J. Miller, L. Mrowczynska, R.J. Wiglusz, Preparation and preliminary evaluation of bionanocomposites based on hydroxyapatites with antibacterial properties against anaerobic bacteria, Materials Science and Engineering: C. 106 (2020) 110295. https://doi.org/10.1016/j.msec.2019.110295.

[17] B. Li, X. Xia, M. Guo, Y. Jiang, Y. Li, Z. Zhang, S. Liu, H. Li, C. Liang, H. Wang, Biological and antibacterial properties of the micro-nanostructured hydroxyapatite/chitosan coating on titanium, Scientific Reports. 9 (2019) 14052. https://doi.org/10.1038/s41598-019-49941-0.

[18] S. Shanmugam, B. Gopal, Antimicrobial and cytotoxicity evaluation of aliovalent substituted hydroxyapatite, Applied Surface Science. 303 (2014) 277-281. https://doi.org/10.1016/j.apsusc.2014.02.166.

[19] S. Shanmugam, B. Gopal, Copper substituted hydroxyapatite and fluorapatite: Synthesis, characterization and antimicrobial properties, Ceramics International. 40 (2014) 15655-15662. https://doi.org/10.1016/j.ceramint.2014.07.086.

[20] V. Stanić, S. Dimitrijević, J. Antić-Stanković, M. Mitrić, B. Jokić, I.B. Plećaš, S. Raičević, Synthesis, characterization and antimicrobial activity of copper and zinc-doped hydroxyapatite nanopowders, Applied Surface Science. 256 (2010) 6083-6089. https://doi.org/10.1016/j.apsusc.2010.03.124.

[21] S. Gomes, C. Vichery, S. Descamps, H. Martinez, A. Kaur, A. Jacobs, J.-M. Nedelec, G. Renaudin, Cu-doping of calcium phosphate bioceramics: From mechanism to the control of cytotoxicity, Acta Biomaterialia. 65 (2018) 462-474. https://doi.org/10.1016/j.actbio.2017.10.028.

[22] J. Forsgren, U. Brohede, M. Strømme, H. Engqvist, Co-loading of bisphosphonates and antibiotics to a biomimetic hydroxyapatite coating, Biotechnology Letters. 33 (2011) 12651268. https://doi.org/10.1007/s10529-011-0542-7.

[23] J.H. Sörensen, M. Lilja, T.C. Sörensen, M. Åstrand, P. Procter, S. Fuchs, M. Strømme, H. Steckel, Biomechanical and antibacterial properties of Tobramycin loaded hydroxyapatite coated fixation pins: Functional Ha Coatings as Local Drug Delivery Vehicles, Journal of Biomedical Materials Research Part B: Applied Biomaterials. 102 (2014) 1381-1392. https://doi.org/10.1002/jbm.b.33117.

[24] U. Brohede, J. Forsgren, S. Roos, A. Mihranyan, H. Engqvist, M. Strømme, Multifunctional implant coatings providing possibilities for fast antibiotics loading with subsequent slow release, Journal of Materials Science: Materials in Medicine. 20 (2009) 1859-1867. https://doi.org/10.1007/s10856-009-3749-6.

[25] M. Lilja, J.H. Sörensen, U. Brohede, M. Åstrand, P. Procter, J. Arnoldi, H. Steckel, M. Strømme, Drug loading and release of Tobramycin from hydroxyapatite coated fixation pins, Journal of Materials Science: Materials in Medicine. 24 (2013) 2265-2274. https://doi.org/10.1007/s10856013-4979-1.

[26] S. Tang, B. Tian, Q.-F. Ke, Z.-A. Zhu, Y.-P. Guo, Gentamicin-loaded carbonated hydroxyapatite coatings with hierarchically porous structures: drug delivery properties, bactericidal properties and biocompatibility, RSC Adv. 4 (2014) 41500-41509. https://doi.org/10.1039/C4RA05493H.

[27] M.A. Fischbach, C.T. Walsh, Antibiotics for Emerging Pathogens, Science. 325 (2009) 10891093.

[28] S.B. Levy, B. Marshall, Antibacterial resistance worldwide: causes, challenges and responses, Nature Medicine. 10 (2004) S122-S129. https://doi.org/10.1038/nm1145.

[29] M.M. Cowan, Plant Products as Antimicrobial Agents, Clin Microbiol Rev. 12 (1999) 564-582.

[30] M. Daglia, Polyphenols as antimicrobial agents, Current Opinion in Biotechnology. 23 (2012) 174-181. https://doi.org/10.1016/j.copbio.2011.08.007.

[31] Y. Lu, R. Joerger, C. Wu, Study of the Chemical Composition and Antimicrobial Activities of Ethanolic Extracts from Roots of Scutellaria baicalensis Georgi, Journal of Agricultural and Food Chemistry. 59 (2011) 10934-10942. https://doi.org/10.1021/jf202741x.

[32] X. Shang, X. He, X. He, M. Li, R. Zhang, P. Fan, Q. Zhang, Z. Jia, The genus Scutellaria an ethnopharmacological and phytochemical review, Journal of Ethnopharmacology. 128 (2010) 279-313. https://doi.org/10.1016/j.jep.2010.01.006. 
[33] B. Dinda, S. Dinda, S. DasSharma, R. Banik, A. Chakraborty, M. Dinda, Therapeutic potentials of baicalin and its aglycone, baicalein against inflammatory disorders, European Journal of Medicinal Chemistry. 131 (2017) 68-80. https://doi.org/10.1016/j.ejmech.2017.03.004.

[34] Y. Gao, S.A. Snyder, J.N. Smith, Y.C. Chen, Anticancer properties of baicalein: a review, Medicinal Chemistry Research. 25 (2016) 1515-1523. https://doi.org/10.1007/s00044-016-1607$\mathrm{X}$.

[35] Y. Chen, T. Liu, K. Wang, C. Hou, S. Cai, Y. Huang, Z. Du, H. Huang, J. Kong, Y. Chen, Baicalein Inhibits Staphylococcus aureus Biofilm Formation and the Quorum Sensing System In Vitro, PLOS ONE. 11 (2016) e0153468. https://doi.org/10.1371/journal.pone.0153468.

[36] B.C.L. Chan, M. Ip, C.B.S. Lau, S.L. Lui, C. Jolivalt, C. Ganem-Elbaz, M. Litaudon, N.E. Reiner, H. Gong, R.H. See, K.P. Fung, P.C. Leung, Synergistic effects of baicalein with ciprofloxacin against NorA over-expressed methicillin-resistant Staphylococcus aureus (MRSA) and inhibition of MRSA pyruvate kinase, Journal of Ethnopharmacology. 137 (2011) 767-773. https://doi.org/10.1016/j.jep.2011.06.039.

[37] W.S.W. Harun, R.I.M. Asri, J. Alias, F.H. Zulkifli, K. Kadirgama, S.A.C. Ghani, J.H.M. Shariffuddin, A comprehensive review of hydroxyapatite-based coatings adhesion on metallic biomaterials, Ceramics International. 44 (2018) 1250-1268. https://doi.org/10.1016/j.ceramint.2017.10.162.

[38] T. Kokubo, Apatite formation on surfaces of ceramics, metals and polymers in body environment, Acta Materialia. 46 (1998) 2519-2527.

[39] K. Achelhi, S. Masse, G. Laurent, A. Saoiabi, A. Laghzizil, T. Coradin, Role of carboxylate chelating agents on the chemical, structural and textural properties of hydroxyapatite, Dalton Transactions. 39 (2010) 10644. https://doi.org/10.1039/c0dt00251h.

[40] B.D. Cullity, S.R. Stock, Elements of X-Ray Diffraction, 3rd Edition, Pearson, 2001.

[41] D.G. Cory, W.M. Ritchey, Suppression of signals from the probe in bloch decay spectra, Journal of Magnetic Resonance (1969). 80 (1988) 128-132. https://doi.org/10.1016/00222364(88)90064-9.

[42] E.L. Hahn, Spin Echoes, Phys. Rev. 80 (1950) 580-594. https://doi.org/10.1103/PhysRev.80.580.

[43] C. Jäger, T. Welzel, W. Meyer-Zaika, M. Epple, A solid-state NMR investigation of the structure of nanocrystalline hydroxyapatite, Magnetic Resonance in Chemistry. 44 (2006) 573580. https://doi.org/10.1002/mrc.1774.

[44] D. Marion, M. Ikura, R. Tschudin, A. Bax, Rapid recording of 2D NMR spectra without phase cycling. Application to the study of hydrogen exchange in proteins, Journal of Magnetic Resonance (1969). 85 (1989) 393-399. https://doi.org/10.1016/0022-2364(89)90152-2.

[45] B.M. Fung, A.K. Khitrin, K. Ermolaev, An Improved Broadband Decoupling Sequence for Liquid Crystals and Solids, Journal of Magnetic Resonance. 142 (2000) 97-101. https://doi.org/10.1006/jmre.1999.1896.

[46] M.S. Blois, Antioxidant determination by the use of a stable free radical, Nature. 181 (1958) 1199-1200.

[47] M.I. Alvarez Echazú, C.E. Olivetti, C. Anesini, C.J. Perez, G.S. Alvarez, M.F. Desimone, Development and evaluation of thymol-chitosan hydrogels with antimicrobial-antioxidant activity for oral local delivery, Materials Science and Engineering: C. 81 (2017) 588-596. https://doi.org/10.1016/j.msec.2017.08.059.

[48] F. Pourpoint, C. Gervais, L. Bonhomme-Coury, T. Azaïs, C. Coelho, F. Mauri, B. Alonso, F. Babonneau, C. Bonhomme, Calcium Phosphates and Hydroxyapatite: Solid-State NMR Experiments and First-Principles Calculations, Appl Magn Reson. 32 (2007) 435-457. https://doi.org/10.1007/s00723-007-0040-1.

[49] K. Beshah, C. Rey, M.J. Glimcher, M. Schimizu, R.G. Griffin, Solid state carbon-13 and proton NMR studies of carbonate-containing calcium phosphates and enamel, Journal of Solid State Chemistry. 84 (1990) 71-81. https://doi.org/10.1016/0022-4596(90)90185-Z.

[50] D.K. Pattanayak, S. Yamaguchi, T. Matsushita, T. Nakamura, T. Kokubo, Apatite-forming ability of titanium in terms of $\mathrm{pH}$ of the exposed solution, Journal of The Royal Society Interface. 9 (2012) 2145-2155. https://doi.org/10.1098/rsif.2012.0107. 
[51] R. Legros, N. Balmain, G. Bonel, Age-related changes in mineral of rat and bovine cortical bone, Calcif Tissue Int. 41 (1987) 137-144. https://doi.org/10.1007/BF02563793.

[52] I.A. Karampas, C.G. Kontoyannis, Characterization of calcium phosphates mixtures, Vibrational Spectroscopy. 64 (2013) 126-133. https://doi.org/10.1016/j.vibspec.2012.11.003.

[53] G. Penel, C. Delfosse, M. Descamps, G. Leroy, Composition of bone and apatitic biomaterials as revealed by intravital Raman microspectroscopy, Bone. 36 (2005) 893-901. https://doi.org/10.1016/j.bone.2005.02.012.

[54] M. Kazanci, P. Fratzl, K. Klaushofer, E.P. Paschalis, Complementary Information on In Vitro Conversion of Amorphous (Precursor) Calcium Phosphate to Hydroxyapatite from Raman Microspectroscopy and Wide-Angle X-Ray Scattering, Calcif Tissue Int. 79 (2006) 354-359. https://doi.org/10.1007/s00223-006-0011-9.

[55] M.M. Kerssens, P. Matousek, K. Rogers, N. Stone, Towards a safe non-invasive method for evaluating the carbonate substitution levels of hydroxyapatite (HAP) in micro-calcifications found in breast tissue, Analyst. 135 (2010) 3156. https://doi.org/10.1039/c0an00565g.

[56] M. Ben Osman, J.M. Krafft, Y. Millot, F. Averseng, T. Yoshioka, J. Kubo, G. Costentin, Molecular Understanding of the Bulk Composition of Crystalline Nonstoichiometric Hydroxyapatites: Application to the Rationalization of Structure-Reactivity Relationships, European Journal of Inorganic Chemistry. 2016 (2016) 2709-2720. https://doi.org/10.1002/ejic.201600244.

[57] S. Diallo-Garcia, D. Laurencin, J.-M. Krafft, S. Casale, M.E. Smith, H. Lauron-Pernot, G. Costentin, Influence of Magnesium Substitution on the Basic Properties of Hydroxyapatites, The Journal of Physical Chemistry C. 115 (2011) 24317-24327. https://doi.org/10.1021/jp209316k.

[58] W.J. Landis, J.R. Martin, X- ray photoelectron spectroscopy applied to gold- decorated mineral standards of biological interest, Journal of Vacuum Science \& Technology A: Vacuum, Surfaces, and Films. 2 (1984) 1108-1111. https://doi.org/10.1116/1.572680.

[59] D.J. Miller, M.C. Biesinger, N.S. McIntyre, Interactions of CO2 and CO at fractional atmosphere pressures with iron and iron oxide surfaces: one possible mechanism for surface contamination?, Surface and Interface Analysis. 33 (2002) 299-305. https://doi.org/10.1002/sia.1188.

[60] A. Shchukarev, D. Korolkov, XPS Study of group IA carbonates, Central European Science Journals. 2 (2004) 347-362. https://doi.org/10.2478/BF02475578.

[61] T.R. Machado, J.C. Sczancoski, H. Beltrán-Mir, I.C. Nogueira, M.S. Li, J. Andrés, E. Cordoncillo, E. Longo, A novel approach to obtain highly intense self-activated photoluminescence emissions in hydroxyapatite nanoparticles, Journal of Solid State Chemistry. 249 (2017) 64-69. https://doi.org/10.1016/j.jssc.2016.12.018.

[62] K.T. Arul, E. Kolanthai, E. Manikandan, G.M. Bhalerao, V.S. Chandra, J.R. Ramya, U.K. Mudali, K.G.M. Nair, S.N. Kalkura, Green synthesis of magnesium ion incorporated nanocrystalline hydroxyapatite and their mechanical, dielectric and photoluminescence properties, Materials Research Bulletin. 67 (2015) 55-62. https://doi.org/10.1016/j.materresbull.2015.02.054.

[63] C. Zhang, J. Yang, Z. Quan, P. Yang, C. Li, Z. Hou, J. Lin, Hydroxyapatite Nano- and Microcrystals with Multiform Morphologies: Controllable Synthesis and Luminescence Properties, Crystal Growth \& Design. 9 (2009) 2725-2733. https://doi.org/10.1021/cg801353n.

[64] K. Farbod, M.R. Nejadnik, J.A. Jansen, S.C.G. Leeuwenburgh, Interactions Between Inorganic and Organic Phases in Bone Tissue as a Source of Inspiration for Design of Novel Nanocomposites, Tissue Engineering Part B: Reviews. 20 (2014) 173-188. https://doi.org/10.1089/ten.teb.2013.0221.

[65] H.Bouyarmane, S.E. Asri, A. Rami, C. Roux, M.A. Mahly, A. Saoiabi, T. Coradin, A. Laghzizil, Pyridine and phenol removal using natural and synthetic apatites as low cost sorbents: Influence of porosity and surface interactions, Journal of Hazardous Materials. 181 (2010) 736-741. https://doi.org/10.1016/j.jhazmat.2010.05.074.

[66] M. Harja, G. Ciobanu, Studies on adsorption of oxytetracycline from aqueous solutions onto hydroxyapatite, Science of The Total Environment. 628-629 (2018) 36-43. https://doi.org/10.1016/j.scitotenv.2018.02.027. 
[67] L.C. Bell, A.M. Posner, J.P. Quirk, The point of zero charge of hydroxyapatite and fluorapatite in aqueous solutions, Journal of Colloid and Interface Science. 42 (1973) 250-261. https://doi.org/10.1016/0021-9797(73)90288-9.

[68] W.M. Chirdon, W.J. O'Brien, R.E. Robertson, Adsorption of catechol and comparative solutes on hydroxyapatite, Journal of Biomedical Materials Research Part B: Applied Biomaterials. 66 (2003) 532-538.

[69] O.W. Duckworth, S.T. Martin, Surface complexation and dissolution of hematite by C1-C6 dicarboxylic acids at pH = 5.0, Geochimica et Cosmochimica Acta. 65 (2001) 4289-4301. https://doi.org/10.1016/S0016-7037(01)00696-2.

[70] H. Gulley-Stahl, P.A. Hogan, W.L. Schmidt, S.J. Wall, A. Buhrlage, H.A. Bullen, Surface Complexation of Catechol to Metal Oxides: An ATR-FTIR, Adsorption, and Dissolution Study, Environmental Science \& Technology. 44 (2010) 4116-4121. https://doi.org/10.1021/es902040u.

[71] M. Patra, R. Mukherjee, M. Banik, D. Dutta, N.A. Begum, T. Basu, Calcium phosphatequercetin nanocomposite (CPQN): A multi-functional nanoparticle having $\mathrm{pH}$ indicating, highly fluorescent and anti-oxidant properties, Colloids and Surfaces B: Biointerfaces. 154 (2017) 6373. https://doi.org/10.1016/j.colsurfb.2017.03.018.

[72] G. Devanand Venkatasubbu, S. Ramasamy, V. Ramakrishnan, J. Kumar, Nanocrystalline hydroxyapatite and zinc-doped hydroxyapatite as carrier material for controlled delivery of ciprofloxacin, 3 Biotech. 1 (2011) 173-186. https://doi.org/10.1007/s13205-011-0021-9.

[73] J.-L. Jiang, Y.-F. Li, T.-L. Fang, J. Zhou, X.-L. Li, Y.-C. Wang, J. Dong, Vancomycin-loaded nano-hydroxyapatite pellets to treat MRSA-induced chronic osteomyelitis with bone defect in rabbits, Inflamm. Res. 61 (2012) 207-215. https://doi.org/10.1007/s00011-011-0402-x.

[74] L. Ploux, M. Mateescu, L. Guichaoua, J. Valentin, J. Böhmler, K. Anselme, E. Champion, N. Pécout, R. Chotard-Ghodsnia, M. Viana, New colloidal fabrication of bioceramics with controlled porosity for delivery of antibiotics, J Mater Sci. 51 (2016) 8861-8879. https://doi.org/10.1007/s10853-016-0133-z.

[75] O. Geuli, N. Metoki, T. Zada, M. Reches, N. Eliaz, D. Mandler, Synthesis, coating, and drugrelease of hydroxyapatite nanoparticles loaded with antibiotics, J. Mater. Chem. B. 5 (2017) 7819-7830. https://doi.org/10.1039/C7TB02105D.

[76] M. Rivas, L.J. del Valle, A.M. Rodríguez-Rivero, P. Turon, J. Puiggalí, C. Alemán, Loading of Antibiotic into Biocoated Hydroxyapatite Nanoparticles: Smart Antitumor Platforms with Regulated Release, ACS Biomaterials Science \& Engineering. 4 (2018) 3234-3245. https://doi.org/10.1021/acsbiomaterials.8b00353. 


\section{CRediT author statement}

Estelle Palierse: Conceptualization, Investigation, Formal analysis, Visualization, Validation, Writing - Original Draft Christophe Hélary: Methodology, Validation, Writing - Review \& Editing Jean-Marc Krafft: Methodology, Investigation, Validation, Writing - Review \& Editing Isabelle Génois: Investigation, Writing - Review \& Editing Sylvie Masse: Methodology, Investigation, Writing - Review \& Editing Guillaume Laurent: Methodology, Investigation, Visualization, Formal analysis, Writing - Review \& Editing Maria I. Alvarez Echazu: Investigation, Writing - Review \& Editing Mohamed Selmane: Investigation, Writing - Review \& Editing Sandra Casale: Investigation, Writing - Review \& Editing Antoine Miche: Investigation, Writing - Review \& Editing Ben C.L. Chan: Resources, Writing - Review \& Editing Clara B.S. Lau: Resources, Writing - Review \& Editing Margaret Ip : Resources, Writing - Review \& Editing Martin F. Desimone : Methodology, Validation, Writing - Review \& Editing Thibaud Coradin : Funding acquisition, Project administration, Conceptualization, Supervision, Validation, Writing - Original Draft Claude Jolivalt : Funding acquisition, Project administration, Conceptualization, Supervision, Validation, Writing - Original Draft 


\section{Declaration of interests}

$\bigotimes$ The authors declare that they have no known competing financial interests or personal relationships that could have appeared to influence the work reported in this paper.

$\square$ The authors declare the following financial interests/personal relationships which may be considered as potential competing interests: 
Graphical abstract

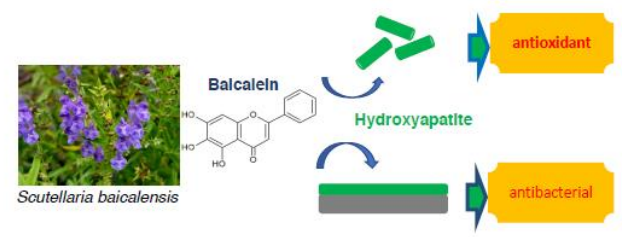




\section{Highlights}

-Hydroxyapatite and baicalein were associated to design biologically-active coatings

-Baicalein-Hydroxyapatite coatings on Ti6AlV4 exhibit antibacterial properties

-Baicalein- Hydroxyapatite nanoparticles are efficient antioxidant agents

-Benefits and limitations of baicalein to functionalize hydroxyapatite are discussed 